Article

\title{
Analysis of Cooling and Heating Degree Days over Mexico in Present and Future Climate
}

\author{
Arturo Corrales-Suastegui ${ }^{1, * \mathbb{C}}$, Osias Ruiz-Alvarez ${ }^{2}$, José Abraham Torres-Alavez ${ }^{3}$ and Edgar G. Pavia ${ }^{4}$ \\ 1 Instituto Nacional de Investigaciones Forestales, Agrícolas y Pecuarias (INIFAP), Campo Experimental \\ Pabellón, Laboratorio Nacional de Modelaje y Sensores Remotos, Pabellón de Arteaga CP 20673, Mexico \\ 2 Instituto Nacional de Investigaciones Forestales Agrícolas y Pecuarias (INIFAP), Campo Experimental Centro \\ de Chiapas (CECECh), Carretera Ocozocoautla-Cintalapa km. 3, Ocozocoautla CP 29140, Mexico; \\ ruiz.osias@inifap.gob.mx \\ 3 Earth System Physics, The Abdus Salam International Centre for Theoretical Physics (ICTP), \\ Strada Costiera, 11, I-34151 Trieste, Italy; jtorres@ictp.it \\ 4 Centro de Investigación Científica y de Educación Superior de Ensenada (CICESE), División de Oceanología, \\ Departamento de Oceanografía Física, Carretera Ensenada-Tijuana No. 3918, Zona Playitas, \\ Ensenada CP 22860, Mexico; epavia@cicese.mx \\ * Correspondence: corrales.arturo@inifap.gob.mx
}

Citation: Corrales-Suastegui, A.; Ruiz-Alvarez, O.; Torres-Alavez, J.A.; Pavia, E.G. Analysis of Cooling and Heating Degree Days over Mexico in Present and Future Climate. Atmosphere 2021, 12, 1131. https:// doi.org/10.3390/atmos12091131

Academic Editor: Graziano Coppa

Received: 27 July 2021

Accepted: 30 August 2021

Published: 2 September 2021

Publisher's Note: MDPI stays neutral with regard to jurisdictional claims in published maps and institutional affiliations.

Copyright: (C) 2021 by the authors. Licensee MDPI, Basel, Switzerland. This article is an open access article distributed under the terms and conditions of the Creative Commons Attribution (CC BY) license (https:// creativecommons.org/licenses/by/ $4.0 /)$.

\begin{abstract}
One simple way to estimate the relationship between air temperature and the energy needed for heating and cooling is to use the concept of degree day. Cooling degree days (CDD) and heating degree days (HDD) are indicators of the energy required to reach comfort levels and are related directly to energy demands. Therefore, using a novel approach, we examine the current conditions and future projections in degree days over Mexico using observations (Livneh and CPC), ERA5 reanalysis, and simulations from the Regional Climate Model (RegCM4). The RegCM4 experiments were driven by different General Circulation Models for two Representative Concentration Pathways scenarios. We consider three 20-year periods as "present conditions" (1995-2014), "near-future conditions" (2041-2060), and "far-future conditions" (2080-2099). The results suggest that in the future, under the lowest radiative forcing scenario there will be a smaller increase (decrease) in CDD (HDD) for the far-future, as compared to the near-future. This could represent the model's response to the peak of radiative forcing at mid-century and its subsequent decline. For the highest radiative forcing scenario, we found a greater increase (decrease) in CDD (HDD) for the far-future, which could be explained by the response of the RegCM4 to the warming increase projected for 2100 .
\end{abstract}

Keywords: CDD; HDD; Mexico; Regional Climate Model; climate change; RegCM4; CORDEX-CAM

\section{Introduction}

The warming of the global climate system is unequivocal, its air surface temperature presents an increase of $0.85^{\circ} \mathrm{C}$ over the 1880 to 2012 period, and the continued emissions of greenhouse gases (GHG) might cause further warming (with a projected increase of 0.3 to $4.8^{\circ} \mathrm{C}$ by the end of the century (2081-2100) relative to (1986-2005); and long-lasting changes in all components of the climate system increase the likelihood of severe, pervasive, and irreversible impacts for people and ecosystems [1].

The Mexico-Central America region is considered one of the most responsive tropical regions to climate change, or Hot Spots [2]. Changes in temperature strongly affect agriculture, water resources, power generation, and especially energy for the heating and cooling of buildings [3-6]. Increasing demands for energy globally have become a matter of concern to the scientific community because of the adverse effect on climatic conditions [5]. To avoid a vicious cycle when procuring human comfort, i.e., increasing energy demands, more adverse climatic conditions, further increase in energy demand, etc., we must rely on renewable energies. The simplest way to express the relationship between temperature and energy for heating and cooling of buildings for human comfort is the concept 
of degree days (DD) [5-7]. Cooling degree days (CDD) and heating degree days (HDD) are indicators of the energy required to reach comfort levels related to energy demands; that is to say, they reflect the energy needed to cool and heat a building, respectively [8]. Degree-days may be defined as the monthly or annual sum of the difference between a threshold temperature (Tr) and a daily mean air temperature $(\mathrm{T})$, whenever $\mathrm{T}$ is higher (lower) than CDD (HDD) [9].

Several works have used the concept of DD to analyze energy consumption requirements in different parts of the world. For example, [7] determined heating and cooling degree-days with variable-base temperatures for Turkey using instrumental data. They found that DD have high variability throughout Turkey, but some regions in the northeastern part require comparatively more heating energy and need less or no cooling. In another work, [10], using observations and global climate models, the authors estimated heating and cooling degree-days for the present-day and future climates over Switzerland. They showed that HDD decrease, whereas CDD continue to increase in future climates. Also, [6] used the RegCM4 to investigate changes in DD in the 21st century over China under different GHG forcing scenarios. They found a substantial decrease in HDD and an increase in CDD in the future under the RCP8.5 scenario, in particular during the second half of the 21st century. A conclusion of this work was that the issue of future energy demand due to changes in DD is complex, with a strong dependence on the spatial variability of climate change. Finally, they concluded that China could expect a large increase in energy demand. Additionally, [11] used the RegCM4.4 to investigate changes in DD in the 21st century for four warming thresholds, with and without considering the population factor. Their results showed a significant decrease of HDD over China when population is not considered, while population-weighted HDD increased in areas where population will increase. Similarly, the CDD projections with and without the population factor were largely different. A conclusion was that the changes in DD considering and disregarding effects of population show that population distribution also plays an important role in energy consumption. More recently, [12] analyzed several climate hazard indices in a global study using a set of observational datasets, global and regional climate simulations ensembles; they found a general increase (decrease) in CDD (HDD) under global warming conditions at the late of the 21st century in several regions of the world, including the Mexico-Central America region.

In Mexico, there are many sites with high solar and wind energetic complementarity where renewable energy generation systems can be developed for the generation of electricity, which is currently mainly based on oil derivatives $[13,14]$. Because the country has a great potential to generate electricity from renewable sources, the government has set a goal of maximum participation of 65 (50) percent of fossil fuels in the generation of electric power by $2025(2050)[14,15]$. Despite this, studies of indices of energy consumption are scarce for Mexico, specifically changes caused by global warming. To examine these changes in indices of energy consumption, such as DD, we will use a Regional Climate Model (RCM) for Mexico driven by different General Circulation Models (GCMs) for different Representative Concentration Pathways (RCP). As far as we know, this is the first work in which cooling and heating degree days are analyzed that are focused on Mexico using observational, reanalysis, and regional climate-simulation datasets for "present" and "future" climate conditions. Therefore, the main purpose of this work is to assess future changes in DD, contributing to energy strategies for Mexico during the 21st century.

\section{Materials and Methods}

\subsection{Model}

The Abdus Salam International Centre for Theoretical Physics (ICTP) Regional Climate Model (RegCM4, v4.7.0) is a hydrostatic, compressible, and 3-dimensional model. It runs on the Arakawa B-grid for the Coordinated Regional Climate Downscaling Experiment (CORDEX), Central America and Mexico (CAM) domain (Figure 1) at $25 \mathrm{~km}$ spatial 
resolution [16-20]. The CORDEX-CAM domain covers completely Mexico (Figure 1a). The RegCM4 model has been used in many climate studies over CAM domain (e.g., [19,21-23]).

(a)

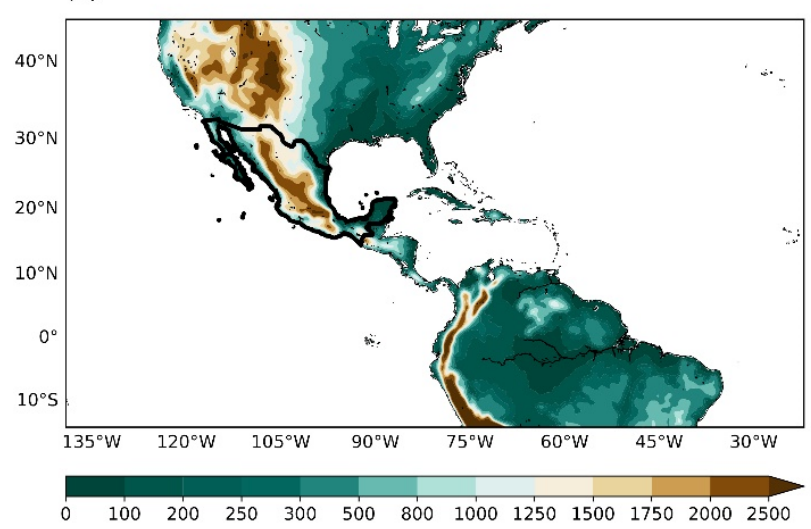

(b)

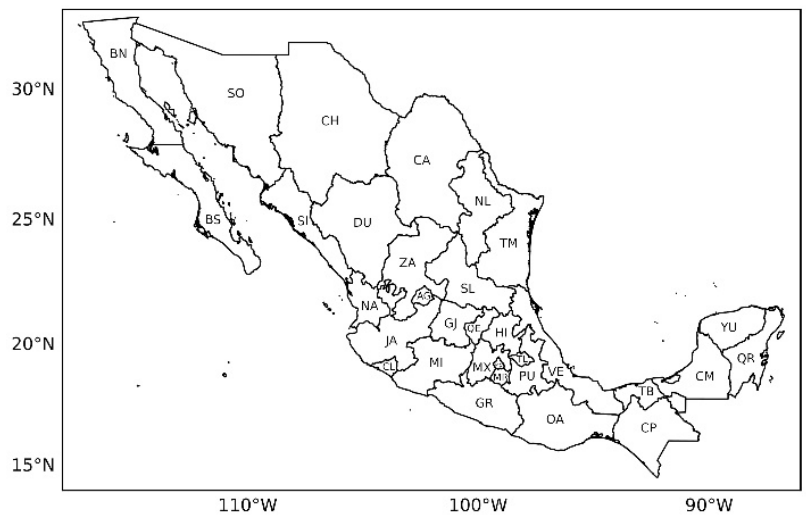

Figure 1. (a) Model domain, topography (m) and study area (in black line). (b) The states of Mexico and their IDs used in this work (see text).

Simulations

Following the IPCC recommendation for AR6, and similar to $[12,19,20]$, we defined the 1995-2014 period as the reference for "present-day conditions" and the 2041-2060 and 2080-2099 periods for "near- and far- future conditions," respectively. For the reference period, we analyzed a simulation (M0) driven by ERA-Interim [24] reanalysis of the European Centre for Medium-Range Weather Forecast (ECMWF, http:/ / apps.ecmwf.int/ datasets /, date of access: 1 April 2020) as an evaluation of the model. We also analyzed simulations driven by three GCMs from the Climate Model Intercomparison Project 5 (CMIP5; [25]):

1. Met Office Hadley Centre, Exeter, United Kingdom, MOHC-HadGEM2-ES, (M1),

2. Max Planck Institute for Meteorology, Hamburg, Germany, MPI-M; M-MPI-ESMLR, (M2),

3. NOAA-Geophysical Fluid Dynamics Laboratory, Princeton University Forrestal Campus, USA, NOAA-GFDL-ESM2M, (M3).

Simulations M1, M2, and M3 were performed for the reference, near, and far future periods under two RCPs: (i) the lowest radiative forcing level scenario, RCP2.6, which is a peak-and-decline scenario; its radiative forcing level first reaches a value of around $3.1 \mathrm{~W} / \mathrm{m}^{2}$ by mid-century and returns to $2.6 \mathrm{~W} / \mathrm{m}^{2}$ by 2100 . The RCP2.6 represents the literature on mitigation scenarios aiming to limit the increase of global mean temperature to $2{ }^{\circ} \mathrm{C}$ [26-28], and (ii) the highest radiative forcing level scenario, RCP8.5. The GHG emissions and concentrations in this scenario increase considerably over time, leading to a radiative forcing of $8.5 \mathrm{~W} / \mathrm{m}^{2}$ at the end of the century. The RCP8.5 is representative of the high range of non-climate policy scenarios $[26,27,29]$. The RCP2.6 and the RCP8.5 were chosen in the CORDEX-CORE protocol because they cover the full IPCC range. Especially, the RCP2.6 produces mean global warming of about $2{ }^{\circ} \mathrm{C}$ compared to preindustrial temperatures and can be considered representative of conditions under the target of the 2015 Paris agreement [19]. We did not make a bias correction. The RegCM4 model was assessed over Mexico, yielding acceptable results (see [21,22]).

We define temperature ensembles for the reference (Eref) and near- and far- future periods (Ercp2.6 and Ercp8.5) by averaging the daily fields of simulations M1 to M3. From the temperature ensembles, we calculated CDD and HDD.

\subsection{Data}

Mexico is characterized by having a varied climate due to its geographic distribution and complex topography. In the north and part of central Mexico, the climate is arid to 
semi-arid. In these regions, the climate is extreme, with very high temperatures in summer and very low in winter. Northwestern Mexico is the most prone to extreme temperatures, and therefore heat waves, frost, etc. On the other hand, some southern regions and coastal areas of Mexico are very wet due to the complex topography, proximity to the Intertropical Convergence Zone, cold fronts, and tropical cyclones (from the Atlantic and the Pacific), among others [30].

In this work, we used three datasets for daily mean temperature:

(i) Livneh observational data-set gridded to a $1 / 16^{\circ}(\sim 6 \mathrm{~km})$ resolution, that spans the entire country of Mexico, USA, and southern Canada for the period 1950-2013 ([31], ftp:/ /192.12.137.7/pub/dcp/archive/OBS/livneh2014.1_16deg/, date of access: 1 June 2020),

(ii) CPC Global Temperature data with $0.50^{\circ}$ resolution for 1 January 1979 to present provided by the NOAA/OAR/ESRL PSL, Boulder, CO, USA, from their Web site at https: / / psl.noaa.gov/, date of access: 15 June 2020, and

(iii) ERA5 reanalysis (spanning 1979 onwards) of the European Centre for MediumRange Weather Forecast (ECMWF) at a horizontal resolution of $31 \mathrm{~km}([32,33]$, https:/ / cds.climate.copernicus.eu/cdsapp\#!/home, date of access: 15 May 2020).

We used each dataset in their original resolution, but in order to compute the biases, the datasets were interpolated to the spatial resolution of the RegCM4.

\subsection{Cooling and Heating Degree Days}

We computed CDD and $\operatorname{HDD}[5,9,11]$ for a threshold temperature of $18^{\circ} \mathrm{C}$, as follows:

$$
\begin{aligned}
& C D D_{k}=\sum_{i=1}^{n} c_{i}^{k}\left(T_{i}^{k}-T_{r}\right) \\
& H D D_{k}=\sum_{i=1}^{n} h_{i}^{k}\left(T_{r}-T_{i}^{k}\right)
\end{aligned}
$$

where $C D D$ and $H D D$ are the cooling and heating degree days in the year $k$, respectively, $i=1,2, \ldots, n$ is the Julian day in the year $k, c_{i}=1$ for $T_{i}>T_{r}$ or $c_{i}=0$ for $T_{i} \leq T_{r}, h_{i}=1$ for $T_{i}<T_{r}$ or $h_{i}=0$ for $T_{i} \geq T_{r}, T_{i}$ is the daily mean temperature for the day $i$, and $T_{r}=18{ }^{\circ} \mathrm{C}$ is the reference temperature. Formulas (1) and (2) give yearly values of CDD and HDD, respectively. From them, we calculate the mean by averaging yearly values over the 20-yr periods (during the reference, near- and far- future).

We computed the time series for the spatial average of $\mathrm{CDD}_{k}(\overline{C D D})$, and $\mathrm{HDD}_{k}$ $(\overline{H D D})$ for the 31 states of Mexico and Mexico City (MC) (Figure 1b). From the resulting time series, we calculated the temporal mean and standard deviation for the reference and near and far future periods.

\section{Results}

\subsection{Reference Period}

We assessed the model performance by comparing M0 with Livneh, CPC, and ERA5. We found that, despite the warm/cold bias in several regions of Mexico, the model has similar characteristics to the observations (Livneh).

\section{Cooling and Heating Degree Days}

We constructed maps by calculating (1) for every grid point in each dataset (Figure 2). Low values of CDD imply less energy for cooling. Low CDD in Livneh (Figure 2a), CPC (Figure 2b), and ERA5 (Figure 2c) are found over Baja California (BN), northern Mexico $\left(500<\mathrm{CDD}<1500{ }^{\circ} \mathrm{C}\right.$ days), north-central Mexico (CDD $<750{ }^{\circ} \mathrm{C}$ days), and central Mexico $\left(\mathrm{CDD}<250^{\circ} \mathrm{C}\right.$ days). The simulations M0, M1, M2, M3, and the ensemble Eref reproduce well this general pattern (not shown). Note that observations show large differences in the values over southern Mexico (Yucatan Peninsula), with the largest values in the CPC. 
(a) Livneh

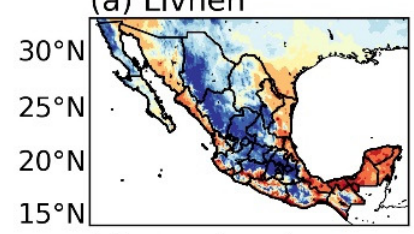

(d) MO-Livneh

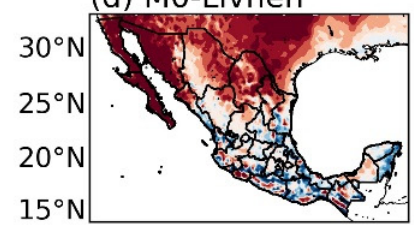

(g) M1-Livneh

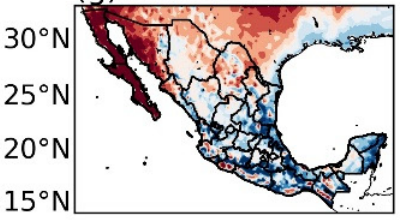

$15^{\circ} \mathrm{N}$
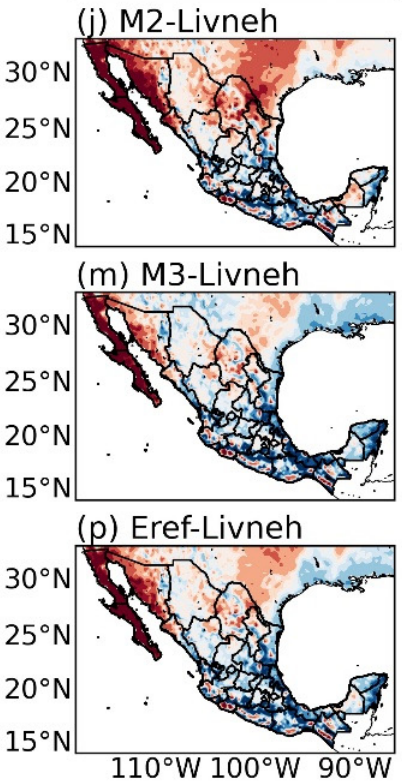

(b) CPC

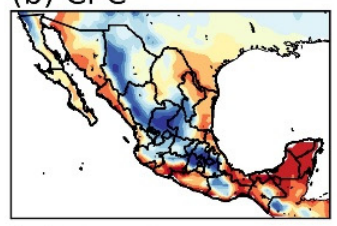

(e) MO-CPC

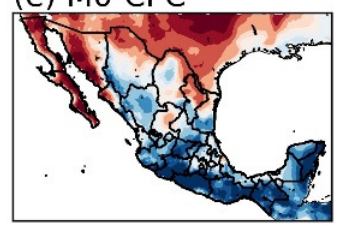

(h) M1-CPC

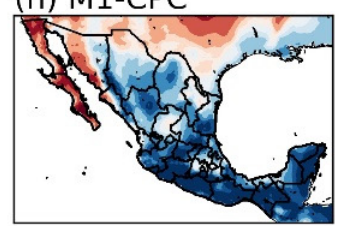

(k) M2-CPC

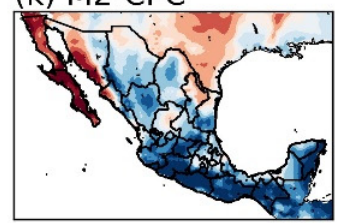

(n) M3-CPC

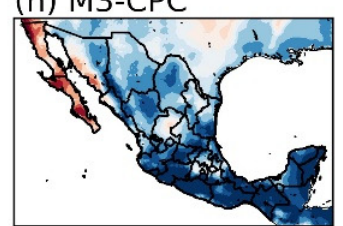

(q) Eref-CPC

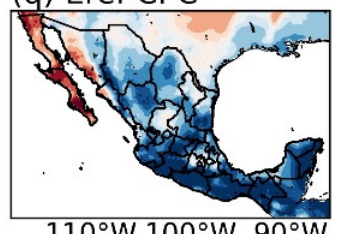

(c) ERA5

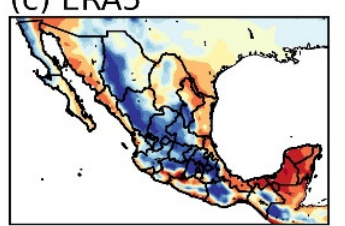

(f) MO-ERA5

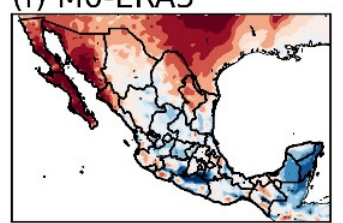

(i) M1-ERA5

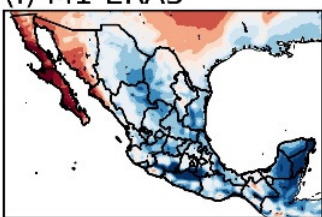

(I) M2-ERA5

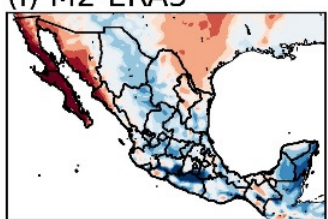

(o) M3-ERA5

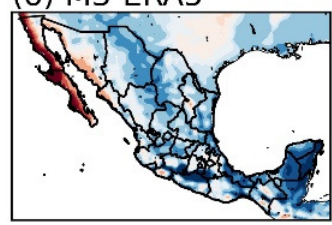

\section{(r) Eref-ERA5}
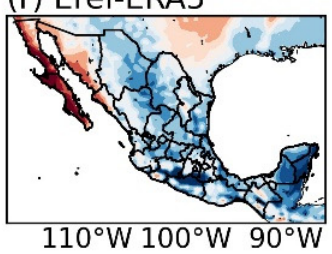
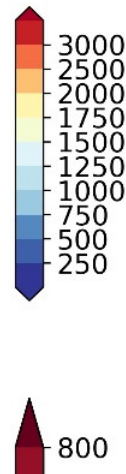

600

400

$-200$

$-100$

$-0$

$-100$

$-200$

$-400$

$-600$

$-800$

Figure 2. The 20-yr average of $\mathrm{CDD}\left({ }^{\circ} \mathrm{C}\right.$ days) for the reference period for (a) Livneh, (b) CPC, and (c) ERA5. Difference in CDD ( ${ }^{\circ} \mathrm{C}$ days) between RegCM4 and observations for (d) M0 minus Livneh, (e) M0 minus CPC, (f) M0 minus ERA5. (g-i) similar to (d-f) but for M1. (j-1) similar to (g-i) but for M2. (m-o) similar to (j-1) but for M3. (p-r) similar to ( $\mathbf{m}-\mathbf{o})$ but for Eref. Period 1995-2014, with the exception of Livneh, which is for 1994-2013.

However, all simulations and Eref have a positive bias over northwestern Mexico (Baja California (BN), Baja California Sur (BS), and Sonora (SO); Figure 2d-r), and the largest negative biases of simulations and Eref are found in high and coastal regions. By definition of (1), a positive bias in CDD means that the model is warm. On the contrary, a negative bias in CDD means that the model is cold consistent with other RegCM4 works in the CAM domain [21,23]. The model bias in percent can be found in Supplementary Materials Figure S1. In general, the largest biases between simulations and Eref with respect to observations were found for CPC (Table 1). 
Table 1. Model bias of CDD area-averaged for Mexico (see Figure 2) with respect to Livneh, CPC, and ERA5 for the period 1995-2014, with the exception of Livneh, which is for 1994-2013. Bias is expressed in degree-days and percent $\left({ }^{\circ} \mathrm{C}\right.$ days $\left.(\%)\right)$.

\begin{tabular}{cccc}
\hline Simulations & \multicolumn{3}{l}{ Observations } \\
\hline & Livneh & CPC & ERA5 \\
\hline M0 & $191.7(13.8)$ & $-177.0(-10.0)$ & $65.3(4.3)$ \\
M1 & $-42.0(-3.0)$ & $-410.7(-23.3)$ & $-168.4(-11.1)$ \\
M2 & $75.5(5.4)$ & $-293.2(-16.6)$ & $-50.9(-3.4)$ \\
M3 & $-125.4(-9.0)$ & $-494.1(-28.1)$ & $-251.8(-16.6)$ \\
Eref & $-76.3(-5.5)$ & $-445.0(-25.3)$ & $-202.7(-13.3)$ \\
\hline
\end{tabular}

In Table 2, we present the mean $(m)$ and the standard deviation (std) of the time series of $\overline{C D D}$ (not shown) for each state of Mexico. We observe that Livneh and CPC have the maximum $m$ value in Tabasco (TB) $\left(\sim 3203 \pm 141\right.$ and $\sim 3419 \pm 124{ }^{\circ} \mathrm{C}$ days, respectively), whereas ERA5 has the maximum $m$ value in Campeche $(\mathrm{CM})\left(\sim 3258 \pm 101{ }^{\circ} \mathrm{C}\right.$ days $)$. M0 ( 3136 $\pm 148{ }^{\circ} \mathrm{C}$ days), M1 ( 3014 $\pm 142{ }^{\circ} \mathrm{C}$ days $)$, M2 ( 3116 $\pm 208{ }^{\circ} \mathrm{C}$ days $)$, M3 ( 2643 $\pm 168^{\circ} \mathrm{C}$ days), and Eref ( 2909 $\pm 127^{\circ} \mathrm{C}$ days) have the maximum $m$ value in Tabasco (TB); the maxima values occur in Tabasco (TB) and Campeche (CM), as they are two of the warmest states in Mexico [34]. Simulations M0 to M3 have comparable values with Livneh and CPC.

Table 2. Mean $(m)$, and the standard deviation $(s t d)$ of $\overline{C D D}$ from several datasets for the reference period.

\begin{tabular}{|c|c|c|c|c|c|c|c|c|c|c|c|c|c|c|c|c|}
\hline \multirow[t]{2}{*}{ State } & \multicolumn{2}{|c|}{ Livneh } & \multicolumn{2}{|c|}{ CPC } & \multicolumn{2}{|c|}{ ERA5 } & \multicolumn{2}{|c|}{ M0 } & \multicolumn{2}{|c|}{ M1 } & \multicolumn{2}{|c|}{ M2 } & \multicolumn{2}{|c|}{ M3 } & \multicolumn{2}{|c|}{ Eref } \\
\hline & $m$ & std & $m$ & std & $m$ & Std & $m$ & std & $m$ & std & $m$ & std & $m$ & std & $m$ & std \\
\hline $\mathrm{AG}$ & 377.3 & 57.2 & 640.6 & 139.7 & 471.5 & 87.2 & 309.0 & 81.6 & 150.8 & 51.1 & 215.1 & 81.8 & 155.4 & 60.8 & 133.7 & 49.8 \\
\hline $\mathrm{BN}$ & 946.1 & 154.4 & 1490.9 & 165.9 & 1280.3 & 81.9 & 1937.7 & 151.8 & 1897.7 & 105.3 & 2049.5 & 168.6 & 1815.3 & 134.6 & 1860.9 & 77.2 \\
\hline BS & 1463.8 & 223.6 & 1926.7 & 156.7 & 1725.5 & 118.7 & 2401.9 & 128.6 & 2420.8 & 114.5 & 2800.3 & 152.3 & 2359.0 & 122.4 & 2482.1 & 79.6 \\
\hline $\mathrm{CM}$ & 2788.9 & 110.7 & 3254.7 & 83.5 & 3258.2 & 101.8 & 2859.4 & 109.2 & 2660.3 & 105.0 & 2877.8 & 183.1 & 2603.7 & 134.0 & 2699.1 & 109.8 \\
\hline $\mathrm{CP}$ & 1933.2 & 78.1 & 2476.7 & 97.5 & 1741.9 & 92.0 & 1689.6 & 99.7 & 1501.0 & 100.9 & 1611.2 & 172.0 & 1425.7 & 138.7 & 1474.4 & 105.6 \\
\hline $\mathrm{CH}$ & 740.1 & 62.3 & 1081.2 & 75.7 & 1027.3 & 94.2 & 1139.1 & 133.6 & 829.7 & 107.9 & 859.6 & 110.6 & 701.7 & 105.0 & 750.9 & 81.0 \\
\hline CA & 1285.9 & 110.9 & 1766.9 & 142.0 & 1644.3 & 156.2 & 1814.5 & 197.7 & 1393.8 & 158.8 & 1556.0 & 172.0 & 1327.3 & 174.8 & 1349.9 & 115.7 \\
\hline CL & 2299.5 & 86.1 & 3004.5 & 129.9 & 2373.7 & 92.0 & 1910.4 & 83.5 & 1841.8 & 83.0 & 1832.9 & 115.5 & 1618.6 & 121.9 & 1741.0 & 89.4 \\
\hline $\mathrm{MC}$ & 67.6 & 38.3 & 43.9 & 30.8 & 7.9 & 8.9 & 7.5 & 15.5 & 0.4 & 1.2 & 1.7 & 5.5 & 2.5 & 4.9 & 0.0 & 0.0 \\
\hline DU & 522.1 & 54.8 & 920.8 & 82.5 & 684.0 & 79.9 & 663.0 & 96.8 & 445.5 & 63.9 & 539.5 & 79.4 & 452.1 & 76.3 & 438.7 & 54.7 \\
\hline GJ & 403.9 & 53.0 & 1069.3 & 111.2 & 488.0 & 84.6 & 302.1 & 77.3 & 150.6 & 53.0 & 213.3 & 91.8 & 168.1 & 59.4 & 133.3 & 49.4 \\
\hline GR & 1917.2 & 91.2 & 2729.5 & 99.4 & 2014.6 & 67.4 & 1595.1 & 66.7 & 1362.2 & 97.7 & 1393.4 & 138.8 & 1375.7 & 149.2 & 1356.2 & 99.1 \\
\hline $\mathrm{HI}$ & 585.8 & 85.6 & 564.4 & 45.7 & 536.3 & 54.2 & 444.4 & 77.0 & 293.1 & 46.0 & 380.0 & 88.4 & 320.2 & 60.0 & 286.4 & 36.8 \\
\hline JA & 1013.0 & 72.0 & 1417.6 & 98.3 & 979.1 & 70.4 & 916.5 & 74.3 & 739.9 & 61.2 & 797.3 & 95.0 & 697.1 & 83.5 & 717.2 & 64.5 \\
\hline MX & 349.2 & 38.7 & 520.4 & 59.9 & 279.2 & 30.0 & 256.3 & 31.5 & 174.8 & 25.4 & 202.3 & 40.2 & 194.3 & 31.7 & 179.5 & 22.9 \\
\hline MI & 1356.9 & 87.2 & 2082.0 & 103.0 & 1424.1 & 56.8 & 1209.0 & 66.5 & 999.8 & 76.3 & 1049.4 & 104.0 & 994.2 & 97.1 & 992.7 & 69.9 \\
\hline MR & 1382.8 & 132.8 & 1844.9 & 171.1 & 1406.8 & 76.9 & 820.5 & 96.8 & 538.6 & 95.3 & 634.2 & 136.3 & 589.9 & 105.7 & 555.9 & 88.1 \\
\hline NA & 1818.3 & 72.0 & 1830.4 & 132.9 & 1629.4 & 93.8 & 1480.3 & 68.1 & 1416.7 & 57.6 & 1452.9 & 91.5 & 1292.9 & 104.0 & 1353.6 & 72.6 \\
\hline NL & 1529.3 & 147.3 & 1712.1 & 126.2 & 1691.9 & 141.0 & 1912.7 & 185.0 & 1529.8 & 136.9 & 1728.5 & 177.3 & 1483.6 & 158.9 & 1497.8 & 98.2 \\
\hline OA & 1601.1 & 107.5 & 2072.1 & 96.5 & 1372.8 & 59.3 & 1198.6 & 64.2 & 1021.1 & 82.4 & 1091.0 & 124.5 & 974.0 & 110.9 & 990.3 & 75.8 \\
\hline PU & 794.8 & 73.2 & 1105.8 & 64.5 & 787.7 & 53.6 & 562.8 & 69.9 & 385.3 & 56.3 & 468.8 & 94.6 & 399.9 & 63.8 & 378.4 & 47.3 \\
\hline QE & 490.4 & 79.8 & 801.0 & 87.7 & 493.7 & 77.7 & 382.6 & 86.6 & 205.7 & 58.4 & 301.7 & 101.6 & 241.9 & 66.6 & 195.2 & 49.6 \\
\hline QR & 2733.8 & 129.9 & 3303.0 & 84.4 & 2965.8 & 106.1 & 2368.7 & 74.8 & 2136.5 & 93.3 & 2390.0 & 126.4 & 2114.9 & 97.0 & 2199.3 & 86.7 \\
\hline$\widehat{S L}$ & 953.2 & 120.2 & 1069.8 & 87.3 & 888.8 & 85.5 & 769.6 & 110.1 & 519.1 & 71.7 & 673.5 & 129.8 & 578.8 & 88.9 & 527.2 & 70.1 \\
\hline SI & 2172.3 & 114.9 & 2519.2 & 107.0 & 2115.2 & 92.1 & 2278.3 & 86.2 & 2195.5 & 78.2 & 2297.2 & 103.1 & 1947.3 & 117.3 & 2105.1 & 82.0 \\
\hline $\mathrm{SO}$ & 1705.7 & 65.9 & 2097.9 & 120.0 & 1918.3 & 100.2 & 2454.9 & 112.5 & 2160.3 & 107.5 & 2228.8 & 137.2 & 1889.6 & 131.9 & 2040.2 & 85.1 \\
\hline TB & 3203.3 & 141.5 & 3419.0 & 124.5 & 3124.0 & 96.2 & 3136.2 & 148.7 & 3014.9 & 142.7 & 3116.7 & 208.6 & 2643.2 & 168.0 & 2909.8 & 127.7 \\
\hline TM & 2104.7 & 119.1 & 2291.3 & 129.0 & 2115.3 & 116.2 & 2146.3 & 131.9 & 1795.4 & 104.9 & 2026.8 & 154.4 & 1756.8 & 135.5 & 1785.5 & 84.8 \\
\hline TL & 11.7 & 13.1 & 65.0 & 39.2 & 11.5 & 17.9 & 7.4 & 16.9 & 0.4 & 0.8 & 1.9 & 4.9 & 2.7 & 6.3 & 0.0 & 0.0 \\
\hline VE & 2429.2 & 229.1 & 2548.2 & 84.7 & 2304.7 & 86.5 & 2227.1 & 92.1 & 1962.6 & 102.6 & 2114.1 & 178.9 & 1725.4 & 137.4 & 1889.4 & 95.6 \\
\hline YU & 2900.8 & 118.8 & 3278.6 & 95.4 & 3036.8 & 114.3 & 2763.7 & 87.0 & 2528.3 & 99.9 & 2823.6 & 153.2 & 2482.5 & 127.2 & 2597.4 & 104.9 \\
\hline ZA & 343.7 & 63.1 & 416.8 & 67.4 & 555.5 & 86.0 & 421.4 & 98.0 & 230.3 & 63.2 & 323.3 & 96.3 & 258.7 & 67.7 & 225.9 & 57.2 \\
\hline
\end{tabular}

On the other hand, we observed that Livneh has the minimum $m$ value in Tlaxcala (TL) $(\sim 11 \pm 13)$, whereas CPC and ERA5 have it in Mexico City (MC) $(\sim 44 \pm 31$ and $\sim 8 \pm 9{ }^{\circ} \mathrm{C}$ days, respectively). The M0 and M1 have the minima value in Tlaxcala (TL) $\left(\sim 7 \pm 17\right.$ and $0.4 \pm 0.8^{\circ} \mathrm{C}$ days, respectively), and we realized that the minima $m$ value in simulations M2 $\left(1.7 \pm 5.5^{\circ} \mathrm{C}\right.$ days $)$ and M3 $\left(2.5 \pm 4.9^{\circ} \mathrm{C}\right.$ days $)$ is in the Mexico City (MC); Eref shows the $m$ minima of $\sim 0.0 \pm 0.0^{\circ} \mathrm{C}$ days in two locations, Mexico City (MC) and 
Tlaxcala (TL). The observations show different locations and values of the minima $m$ value. Only the M0 shows similar values compared with Livneh.

Also, we constructed maps by calculating (2) for every grid point in each dataset (Figure 3). The high values of HDD imply more energetic requirements for heating. We observed HDD values between 1750 and $3000{ }^{\circ} \mathrm{C}$ days in Baja California (BN), and in the highlands of northwestern and central Mexico $\left(1750<\mathrm{HDD}<3000^{\circ} \mathrm{C}\right.$ days) for Livneh (Figure 3a); in the same regions CPC (Figure $3 b$ ) and ERA5 (Figure 3c) show the maxima values, from 1250 to $2000^{\circ} \mathrm{C}$ days. Similar to the CDD (Figure 2), the simulations M0, M1, M2, M3, and Eref reproduce well this pattern (not shown).

(a) Livneh

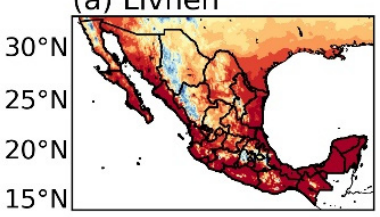

(d) M0-Livneh
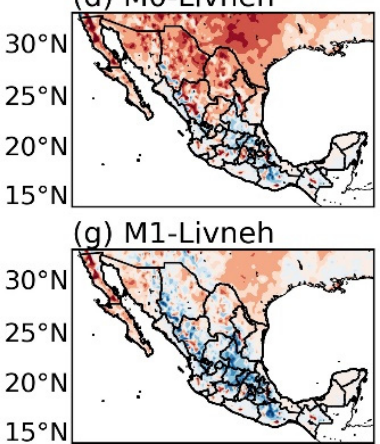

(j) M2-Livneh

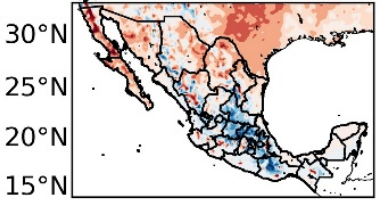

(m) M3-Livneh

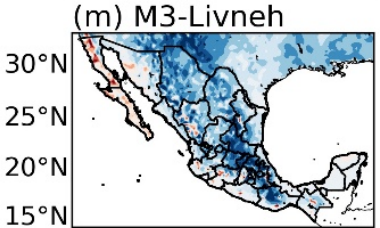

(p) Eref-Livneh

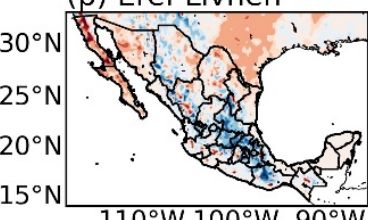

(b) CPC

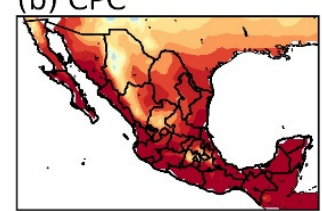

(e) MO-CPC

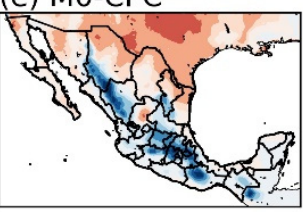

(h) M1-CPC

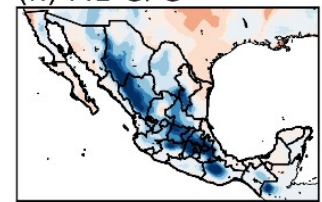

(k) M2-CPC

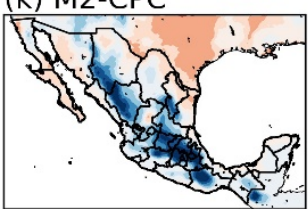

(n) M3-CPC

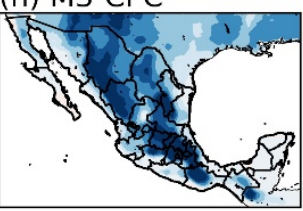

(q) Eref-CPC

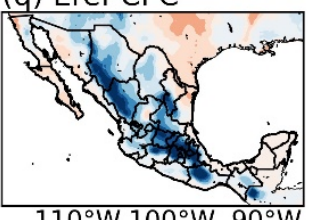

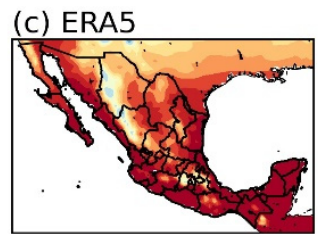

(f) MO-ERA5

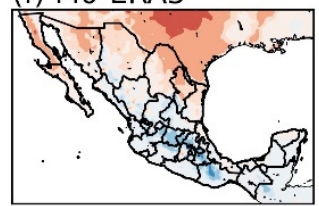

(i) M1-ERA5

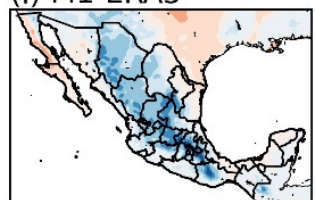

(I) M2-ERA5

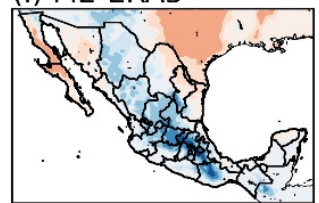

(o) M3-ERA5

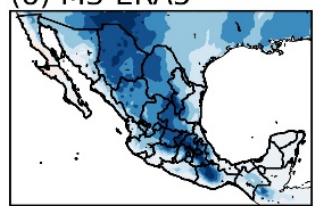

(r) Eref-ERA5

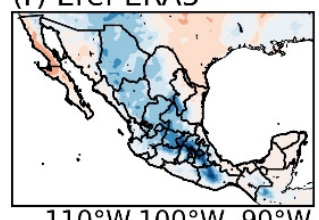

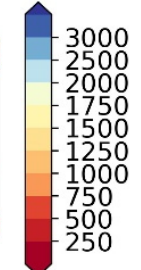

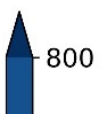

$-600$

$-400$

$-200$

$-100$

$-0$

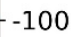

$-200$

$-400$

$-600$

800

Figure 3. The 20-yr average of $\operatorname{HDD}\left({ }^{\circ} \mathrm{C}\right.$ days) for the reference period for (a) Livneh, (b) CPC, and (c) ERA5. Difference in HDD $\left({ }^{\circ} \mathrm{C}\right.$ days) between RegCM4 and observations for (d) M0 minus Livneh, (e) M0 minus CPC, (f) M0 minus ERA5. (g-i) similar to (d-f) but for M1. (j-1) similar to (g-i) but for M2. (m-o) similar to (j-1) but for M3. (p-r) similar to (m-o) but for Eref. Period 1995-2014, with the exception of Livneh, which is for 1994-2013.

However, all simulations and Eref have a negative bias over northwestern Mexico (Figure 3d-r), and the largest positive biases of simulations and Eref are found in high regions. By definition of (2), a positive bias in HDD means that the model is cold; in contrast, a negative bias in HDD means that the model is warm, consistent with what we found for CDD (see Figure 2). The model bias in percent can be found in Supplementary 
Materials Figure S2. Moreover, the largest HDD biases between simulations and Eref relative to observations were found for CPC (Table 3).

Table 3. Model bias of HDD area-averaged for Mexico (see Figure 3) with respect to Livneh, CPC, and ERA5 for the period 1995-2014, with the exception of Livneh, which is for 1994-2013. Bias is expressed in degree-days and percent $\left({ }^{\circ} \mathrm{C}\right.$ days $\left.(\%)\right)$.

\begin{tabular}{cccc}
\hline Simulations & \multicolumn{3}{c}{ Observations } \\
\hline & Livneh & CPC & ERA5 \\
\hline M0 & $-171.8(-26.7)$ & $38.6(8.9)$ & $-23.9(-4.8)$ \\
M1 & $-17.7(-2.8)$ & $192.7(44.6)$ & $130.2(26.3)$ \\
M2 & $-64.7(-10.1)$ & $145.7(33.7)$ & $83.2(16.8)$ \\
M3 & $195.8(30.5)$ & $406.2(94.0)$ & $343.7(69.5)$ \\
Eref & $-26.3(-4.1)$ & $184.1(42.6)$ & $121.6(24.6)$ \\
\hline
\end{tabular}

In Table 4, we present the mean $(m)$ and the standard deviation $(s t d)$ of the time series (not shown) of $\overline{H D D}$ from each state of Mexico. We observe that Livneh has the maximum $m$ value in Tlaxcala (TL) $\left(\sim 1708 \pm 229^{\circ} \mathrm{C}\right.$ days), whereas CPC and ERA5 have the maximum $m$ value in Mexico City (MC) $\left(\sim 1214 \pm 163\right.$ and $\sim 1672 \pm 131^{\circ} \mathrm{C}$ days, respectively). In turn, M0 ( 1656 $\pm 107^{\circ} \mathrm{C}$ days), M1 ( 1931 $\pm 123{ }^{\circ} \mathrm{C}$ days), M2 ( 1957 $\pm 186{ }^{\circ} \mathrm{C}$ days), M3 ( 2180 $\pm 153{ }^{\circ} \mathrm{C}$ days), and Eref $\left(\sim 1990 \pm 112^{\circ} \mathrm{C}\right.$ days $)$ have the maximum $m$ value in Tlaxcala (TL), which is the coolest state in Mexico [34]. Simulations M0, M1, M2, and Eref have values comparable to Livneh. We observed that Livneh and ERA5 have the minima $m$ value in Tabasco (TB) $(0.8 \pm 1$ and $0.4 \pm 0.7$, respectively), whereas CPC has it in Quintana Roo (QR) $\left(0.5 \pm 1.1^{\circ} \mathrm{C}\right.$ days). The minima $m$ value in simulations M0 $\left(0.7 \pm 0.8{ }^{\circ} \mathrm{C}\right.$ days), $\mathrm{M} 1\left(0.4 \pm 0.5^{\circ} \mathrm{C}\right.$ days $), \mathrm{M} 2\left(0.5 \pm 0.7^{\circ} \mathrm{C}\right.$ days $), \mathrm{M} 3\left(3.6 \pm 2.4{ }^{\circ} \mathrm{C}\right.$ days $)$, and Eref $\left(0.0 \pm 0.0^{\circ} \mathrm{C}\right.$ days) was in Yucatán (YU). Over Tabasco (TB) the evaluation (M0), simulations M1 to M3 and the ensemble (Eref) could not reproduce the minima observed in Livneh and ERA5.

Table 4. Mean $(m)$ and standard deviation $(s t d)$ of $\overline{H D D}$ from several datasets for the reference period.

\begin{tabular}{|c|c|c|c|c|c|c|c|c|c|c|c|c|c|c|c|c|}
\hline \multirow[t]{2}{*}{ State } & \multicolumn{2}{|c|}{ Livneh } & \multicolumn{2}{|c|}{ CPC } & \multicolumn{2}{|c|}{ ERA5 } & \multicolumn{2}{|c|}{ M0 } & \multicolumn{2}{|c|}{ M1 } & \multicolumn{2}{|c|}{ M2 } & \multicolumn{2}{|c|}{ M3 } & \multicolumn{2}{|c|}{ Eref } \\
\hline & $m$ & std & $m$ & std & $m$ & Std & $m$ & std & $m$ & std & $m$ & std & $m$ & std & $m$ & std \\
\hline $\mathrm{AG}$ & 727.6 & 88.7 & 507.4 & 97.4 & 587.6 & 81.1 & 713.2 & 94.9 & 943.0 & 95.7 & 915.5 & 129.9 & 1108.5 & 122.9 & 922.5 & 82.5 \\
\hline $\mathrm{BN}$ & 960.1 & 94.0 & 608.8 & 118.1 & 702.5 & 100.1 & 508.4 & 89.5 & 601.4 & 88.3 & 554.3 & 116.0 & 790.0 & 81.9 & 567.1 & 62.8 \\
\hline BS & 291.7 & 51.6 & 169.4 & 58.2 & 172.2 & 49.6 & 96.3 & 40.2 & 82.6 & 32.4 & 29.2 & 14.0 & 154.9 & 35.0 & 44.2 & 10.5 \\
\hline $\mathrm{CM}$ & 2.3 & 2.1 & 1.1 & 1.8 & 0.5 & 1.0 & 1.3 & 1.5 & 0.6 & 0.9 & 1.4 & 1.5 & 6.7 & 3.9 & 0.0 & 0.0 \\
\hline $\mathrm{CP}$ & 111.7 & 16.9 & 13.7 & 6.2 & 60.5 & 14.4 & 70.6 & 18.9 & 72.5 & 14.9 & 93.5 & 28.2 & 169.5 & 33.7 & 73.5 & 13.2 \\
\hline $\mathrm{CH}$ & 1456.8 & 112.5 & 1154.8 & 113.2 & 1181.8 & 107.6 & 1085.2 & 126.9 & 1431.7 & 115.5 & 1304.9 & 167.2 & 1842.3 & 165.4 & 1437.3 & 93.4 \\
\hline $\mathrm{CA}$ & 862.6 & 129.1 & 621.7 & 87.6 & 636.5 & 83.3 & 490.1 & 76.9 & 751.1 & 122.5 & 639.8 & 133.9 & 1158.3 & 154.4 & 742.6 & 89.1 \\
\hline $\mathrm{CL}$ & 47.9 & 12.3 & 1.2 & 3.0 & 0.7 & 0.9 & 13.5 & 11.5 & 19.3 & 12.0 & 15.5 & 6.7 & 65.2 & 23.5 & 12.5 & 5.2 \\
\hline $\mathrm{MC}$ & 1586.5 & 154.7 & 1214.7 & 163.6 & 1672.7 & 131.4 & 1445.8 & 104.7 & 1735.0 & 114.0 & 1735.5 & 168.4 & 1905.5 & 138.9 & 1760.4 & 109.5 \\
\hline DU & 1251.4 & 107.2 & 723.1 & 95.9 & 978.0 & 100.6 & 947.6 & 107.6 & 1230.2 & 91.4 & 1111.3 & 115.9 & 1441.3 & 146.9 & 1187.5 & 75.0 \\
\hline GJ & 600.1 & 75.8 & 245.1 & 61.8 & 499.9 & 68.0 & 681.6 & 72.7 & 890.8 & 93.7 & 923.1 & 140.0 & 1123.2 & 115.2 & 910.9 & 81.7 \\
\hline GR & 79.6 & 14.8 & 4.9 & 3.8 & 18.6 & 5.4 & 38.5 & 14.0 & 55.7 & 16.2 & 74.8 & 22.6 & 102.9 & 21.2 & 57.1 & 12.3 \\
\hline $\mathrm{HI}$ & 804.3 & 82.2 & 635.2 & 78.1 & 738.0 & 71.3 & 926.8 & 69.6 & 1124.8 & 89.6 & 1173.4 & 145.4 & 1448.9 & 126.0 & 1177.2 & 87.5 \\
\hline JA & 356.9 & 48.8 & 188.7 & 61.8 & 205.6 & 42.9 & 282.4 & 50.4 & 384.2 & 49.5 & 368.5 & 68.0 & 484.2 & 61.2 & 372.1 & 40.8 \\
\hline MX & 1395.7 & 69.1 & 762.3 & 96.4 & 1087.6 & 82.1 & 1107.1 & 79.0 & 1328.3 & 92.3 & 1339.7 & 136.8 & 1476.4 & 113.1 & 1346.3 & 89.3 \\
\hline MI & 366.6 & 36.3 & 131.6 & 27.1 & 227.8 & 26.0 & 271.1 & 34.9 & 359.5 & 36.3 & 356.7 & 50.6 & 438.5 & 43.0 & 355.1 & 32.0 \\
\hline MR & 156.0 & 53.7 & 18.9 & 18.2 & 148.4 & 24.9 & 204.7 & 45.9 & 298.8 & 55.4 & 314.6 & 65.9 & 413.6 & 51.9 & 299.8 & 41.3 \\
\hline NA & 122.8 & 27.2 & 63.7 & 31.1 & 76.4 & 28.7 & 128.0 & 38.3 & 167.8 & 35.3 & 144.4 & 39.0 & 253.2 & 55.2 & 148.1 & 26.6 \\
\hline NL & 659.4 & 122.7 & 458.9 & 77.9 & 549.4 & 70.8 & 414.7 & 50.0 & 621.8 & 92.2 & 555.1 & 88.7 & 954.6 & 128.4 & 603.4 & 66.6 \\
\hline OA & 257.6 & 41.4 & 79.9 & 30.5 & 188.6 & 28.0 & 293.0 & 30.8 & 347.7 & 38.8 & 388.4 & 62.9 & 540.9 & 59.0 & 378.9 & 38.4 \\
\hline PU & 800.4 & 95.9 & 382.7 & 47.0 & 541.0 & 51.1 & 719.7 & 59.5 & 883.8 & 76.3 & 901.7 & 113.5 & 1145.8 & 93.9 & 916.7 & 69.4 \\
\hline $\mathrm{QE}$ & 588.1 & 79.2 & 377.6 & 88.7 & 518.3 & 71.5 & 762.7 & 63.0 & 945.2 & 90.4 & 1016.5 & 138.9 & 1286.5 & 124.1 & 1001.1 & 79.7 \\
\hline QR & 2.6 & 2.3 & 0.5 & 1.1 & 0.5 & 0.8 & 2.0 & 2.2 & 1.0 & 1.0 & 1.5 & 1.8 & 7.0 & 4.1 & 0.0 & 0.1 \\
\hline SL & 547.6 & 72.2 & 454.5 & 60.1 & 527.8 & 66.6 & 590.0 & 65.0 & 806.9 & 82.2 & 772.0 & 117.3 & 1100.5 & 122.6 & 804.1 & 65.6 \\
\hline SI & 128.2 & 31.8 & 84.4 & 30.9 & 99.5 & 36.5 & 126.8 & 40.5 & 138.2 & 32.3 & 108.2 & 31.2 & 244.6 & 46.8 & 116.6 & 19.9 \\
\hline SO & 676.5 & 70.1 & 513.6 & 90.2 & 540.1 & 91.1 & 413.0 & 88.2 & 562.8 & 72.1 & 500.4 & 108.2 & 784.9 & 73.4 & 542.6 & 56.6 \\
\hline TB & 0.8 & 1.0 & 0.7 & 1.2 & 0.4 & 0.7 & 1.0 & 0.9 & 0.6 & 0.6 & 1.4 & 1.5 & 11.7 & 5.5 & 0.1 & 0.1 \\
\hline TM & 298.7 & 65.9 & 271.8 & 57.6 & 263.0 & 55.5 & 153.9 & 28.2 & 255.3 & 59.2 & 224.6 & 46.4 & 502.3 & 100.9 & 239.3 & 43.1 \\
\hline TL & 1708.6 & 229.5 & 986.2 & 120.6 & 1430.2 & 109.8 & 1656.1 & 107.2 & 1931.6 & 123.4 & 1957.2 & 186.8 & 2180.5 & 153.3 & 1990.1 & 112.7 \\
\hline VE & 125.2 & 25.7 & 61.9 & 16.0 & 88.9 & 16.7 & 77.7 & 15.1 & 100.7 & 16.0 & 107.5 & 19.9 & 238.3 & 41.0 & 101.3 & 14.3 \\
\hline YU & 3.0 & 3.3 & 0.8 & 1.7 & 0.8 & 1.6 & 0.7 & 0.8 & 0.4 & 0.5 & 0.5 & 0.7 & 3.6 & 2.4 & 0.0 & 0.0 \\
\hline $\mathrm{ZA}$ & 963.7 & 107.2 & 822.0 & 95.7 & 696.5 & 91.7 & 745.9 & 103.6 & 1020.2 & 97.9 & 934.9 & 128.7 & 1181.5 & 144.8 & 972.1 & 81.1 \\
\hline
\end{tabular}




\subsection{Future Period}

\subsubsection{Near-Future (2041-2060)}

In this section, we present the results for the near-future (2041-2060) for simulations M1, M2, and M3 under RCP2.6 and RCP8.5 scenarios, and the corresponding ensemble (Ercp26 and Ercp85).

Cooling and Heating Degree Days

In Figure 4, we show the $C D D$ change $\left(\triangle C D D=C D D_{\text {near-future }}-C_{D D}\right.$ reference $)$, and the $\mathrm{HDD}$ change $\left(\triangle \mathrm{HDD}=\mathrm{HDD}_{\text {near-future }}-\mathrm{HDD}_{\text {reference }}\right)$ following both RCP2.6 and RCP8.5 scenarios.
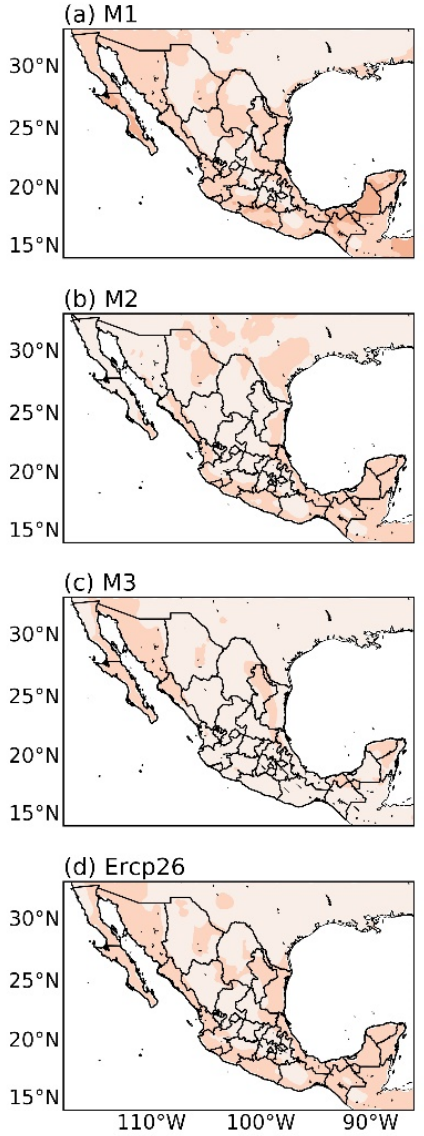
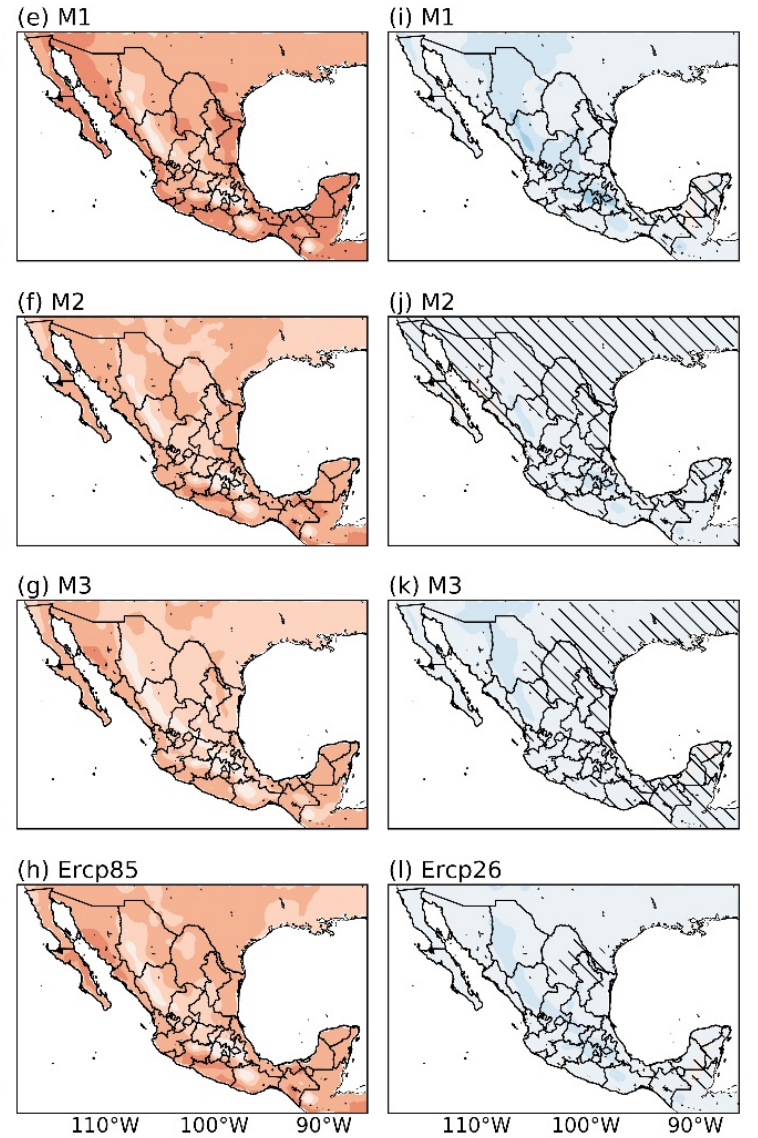
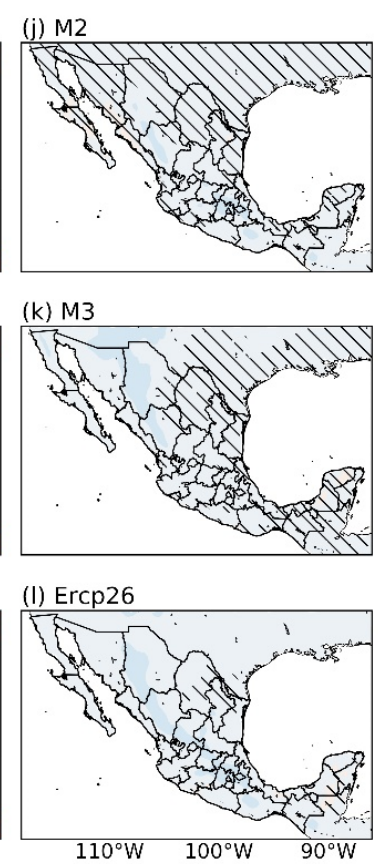
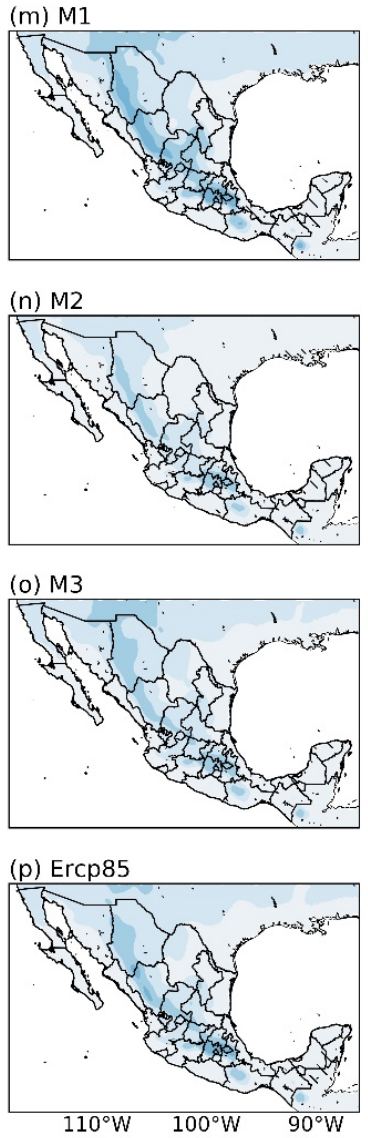

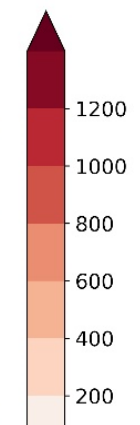

0
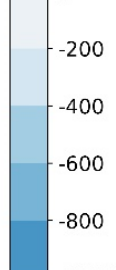

$-1000$

$-1200$

Figure 4. Change in CDD ( ${ }^{\circ} \mathrm{C}$ days) during 2041-2060 for (a) M1, (b) M2, (c) M3, and (d) Ercp26 following the RCP2.6. (e-h) similar to (a-d) but for RCP8.5. Change in HDD ( ${ }^{\circ} \mathrm{C}$ days) during 2041-2060 for (i) M1, (j) M2, (k) M3, and (l) Ercp26 following the RCP2.6. (m-p) similar to (i-1) but for RCP8.5. Hatched lines mean non-significant change at the 95\% confidence interval.

The simulations reveal that the Yucatan Peninsula shows the highest values (between 200 and $400{ }^{\circ} \mathrm{C}$ days) of $\triangle \mathrm{CDD}$ (Figure $4 \mathrm{a}-\mathrm{c}$ ), also in northwestern Mexico (Figure $4 \mathrm{a}, \mathrm{c}$ ), and both Pacific and Gulf coast regions of Mexico (Figure 4a,b). Ercp26 (Figure 4d) shows that in some regions in simulations M1 to M3 under the RCP2.6 scenario, there are no expected major changes; but a shift towards increased CDD over the Yucatan's Peninsula, northwestern Mexico, and coastal regions of the Pacific and the Gulf of Mexico. On the other hand, under the RCP8.5, all simulations (Figure 4e-g) and Ercp8.5 (Figure 4h) show an increase in CDD over the whole country with exceptions for Central Mexico and mountains regions over Oaxaca (OA), Durango (DU), and Chihuahua $(\mathrm{CH})$.

For the HDD change, simulations project small changes in northwestern (Figure 4k), north-central, and central Mexico (Figure 4i). Ercp26 (Figure 4l) shows a consistent decrease of HDD under the RCP2.6 scenario over some regions in northwestern, the north-central, 
and central areas of Mexico. In turn, under the RCP8.5, all simulations (Figure $4 \mathrm{~m}-\mathrm{O}$ ) and Ercp8.5 (Figure 4p) reveal a decrease in HDD $\left(-600^{\circ} \mathrm{C}\right.$ days $<\Delta \mathrm{HDD}<-200^{\circ} \mathrm{C}$ days) over central, north-central, and northwestern Mexico. The decrease in HDD in both RCPs is due to increased mean daily temperature (see equation 2), more noticeable for the RCP8.5, consistent with the warming projected by mid-century [35].

The boxplots (Figure 5) show the change in $m\left(\Delta m=m_{\text {near-future }}-m_{\text {reference }}\right)$ of $\overline{C D D}$ (Figure 5a,b) and $\overline{H D D}$ (Figure 5c,d) for both RCP2.6 (boxplots in black) and RCP8.5 (boxplots in red). Figure 5 a shows the $\triangle m$ of $\overline{C D D}$ computed for the 32 states of Mexico for M1, M2, M3, and Ercp. The highest $\Delta m$ values in the simulations M1 to M3 and Ercp are expected under the RCP8.5 (boxplots in red). Figure 5b shows the $\triangle m$ of $\overline{C D D}$ for each state of Mexico from simulations M1 to M3 and Ercp. Positive $\Delta m$ values are expected under both RCP scenarios. For the RCP8.5, $\Delta m$ could be higher in the 32 states than in Mexico City (MC). Figure $5 c$ shows the $\Delta m$ of $\overline{H D D}$. The lowest $\Delta m$ values of $\overline{H D D}$ in the simulations M1, M3, and Ercp are expected under the RCP8.5 (boxplots in red). Figure 5d shows the $\triangle m$ of $\overline{H D D}$ for each state of Mexico from simulations M1 to M3 and Ercp. Negative $\Delta m$ values are expected in both RCP scenarios for nearly all 32 states in Mexico, but for periods in the more extreme scenario, the change $\Delta m$ could be large. The increase (decrease) in $\overline{C D D}(\overline{H D D})$ is consistent with the warming expected by mid-century [35].

(a)
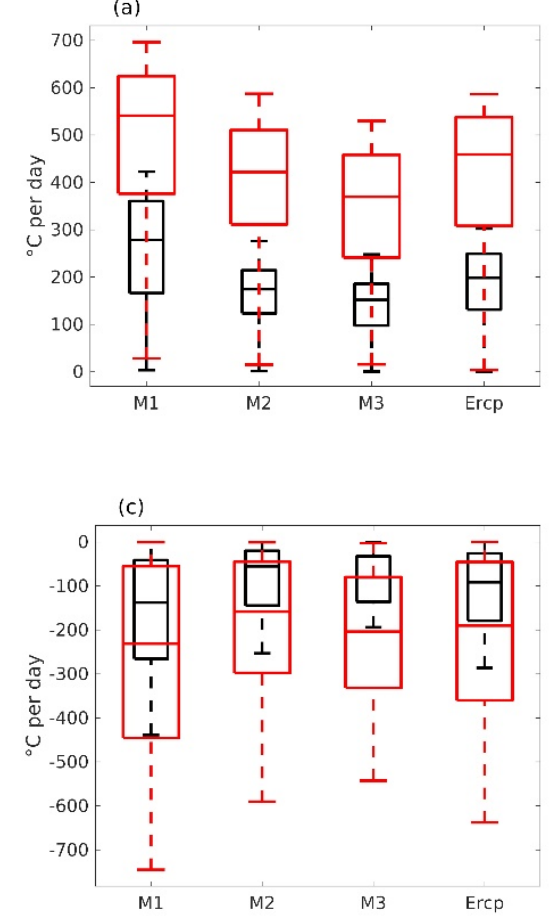

(b)
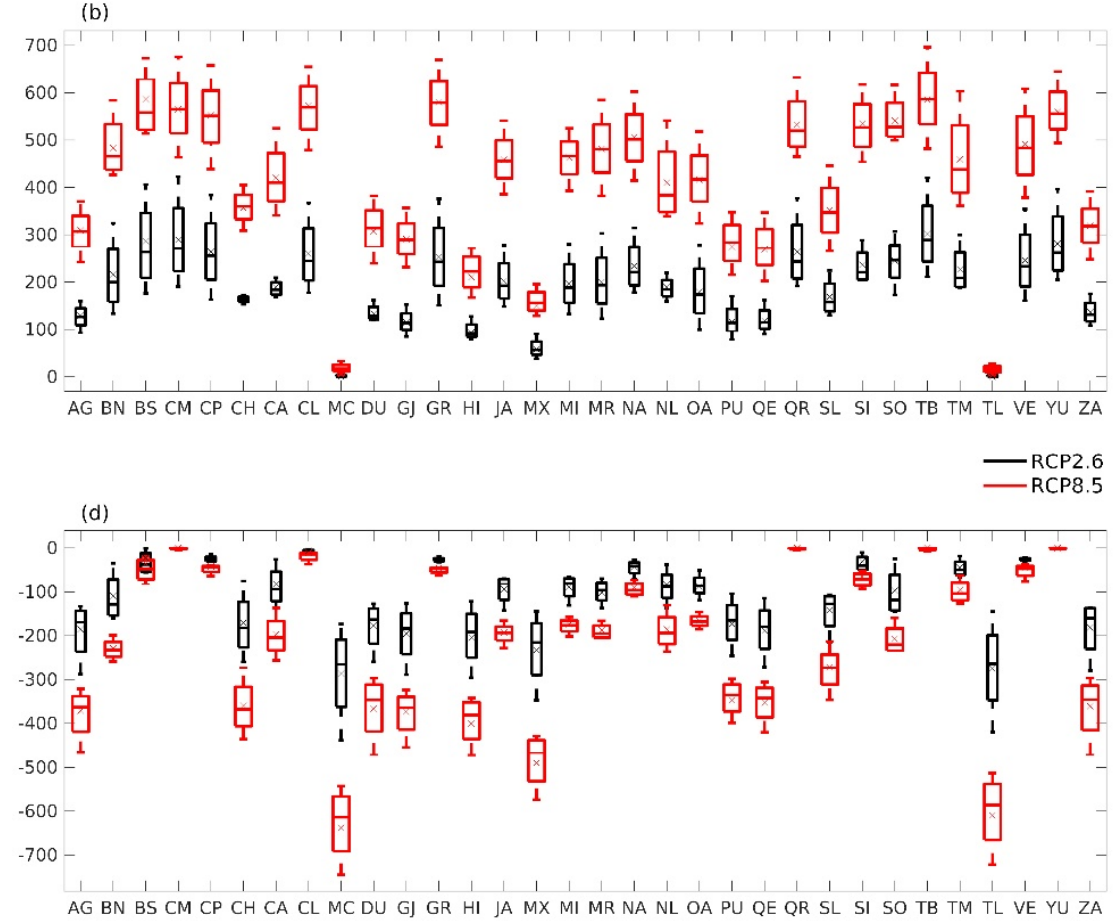

Figure 5. Change in $\overline{C D D}\left({ }^{\circ} \mathrm{C}\right.$ days) during 2041-2060 for (a) M1, M2, M3, and Ercp for the 32 states of Mexico, and (b) in each state of Mexico for M1, M2, M3 and Ercp. (c,d) same as (a,b), respectively, but for the change in $\overline{H D D}$. The cross (x) in $(\mathbf{b}, \mathbf{d})$ indicates the $\Delta m$ for Ercp.

\subsubsection{Far-Future (2080-2099)}

In this section, we present the results for the far future period (2080-2099) for simulations M1, M2, and M3 under the RCP2.6 and RCP8.5 scenarios, and the corresponding ensemble (Ercp26 and Ercp85).

Cooling and Heating Degree Days

In Figure 6 , we show the CDD change $\left(\triangle \mathrm{CDD}=\mathrm{CDD}_{\text {far-future }}-\mathrm{CDD}_{\text {reference }}\right)$ under both RCP2.6 (Figure 6a-d) and RCP8.5 (Figure 6e-h) scenarios; and the HDD change $\left(\triangle \mathrm{HDD}=\mathrm{HDD}_{\text {far-future }}-\mathrm{HDD}_{\text {reference }}\right.$ ) for RCP2.6 (Figure $\left.6 \mathrm{i}-1\right)$, and RCP8.5 (Figure $6 \mathrm{~m}-\mathrm{p}$ ) scenarios. 

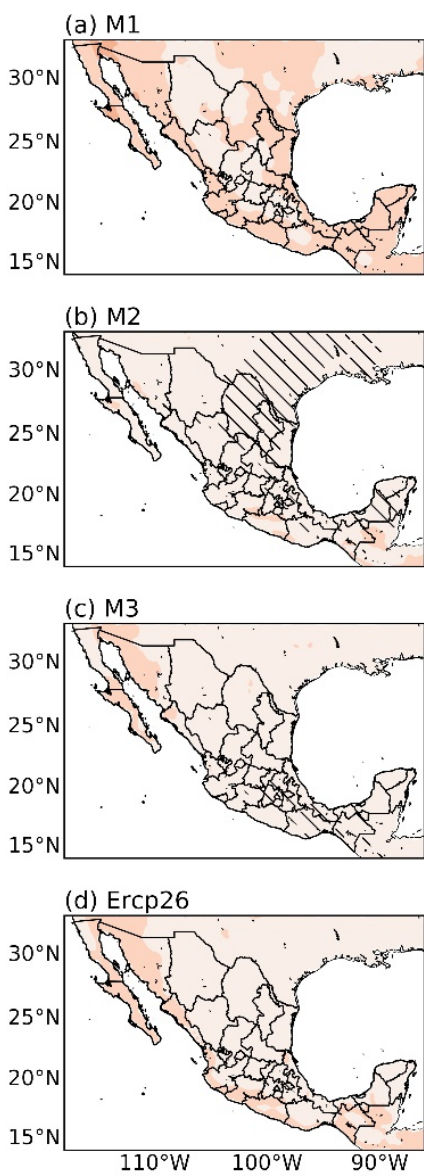
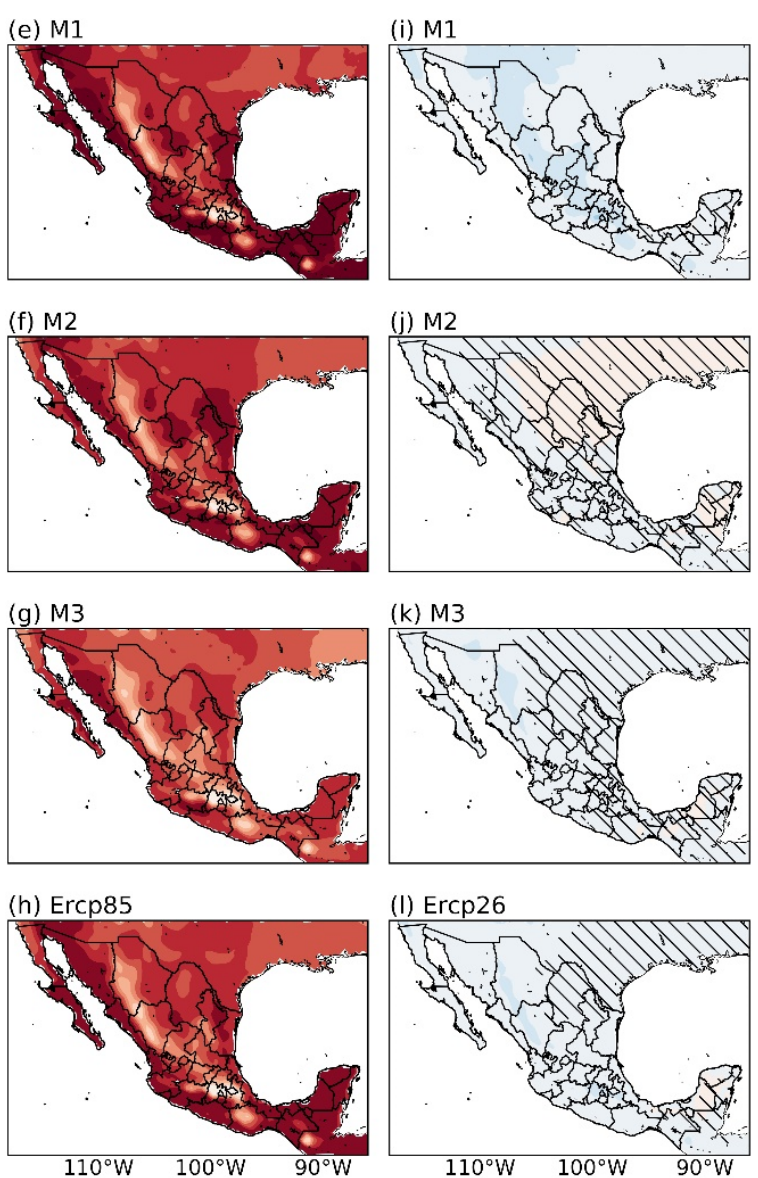
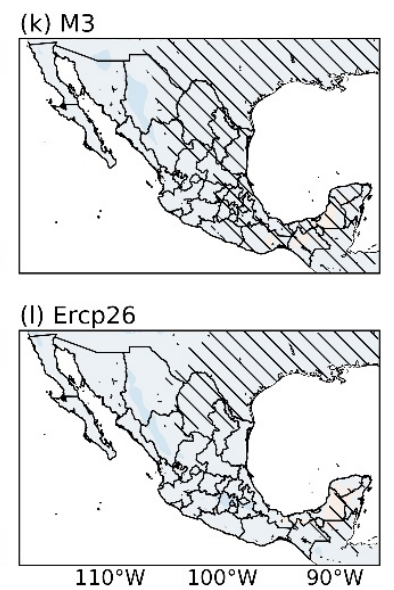
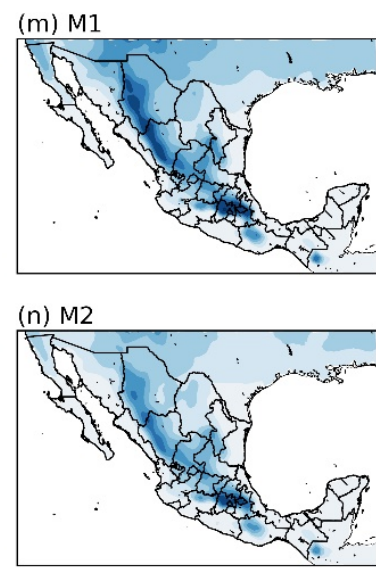

(o) $\mathrm{M3}$
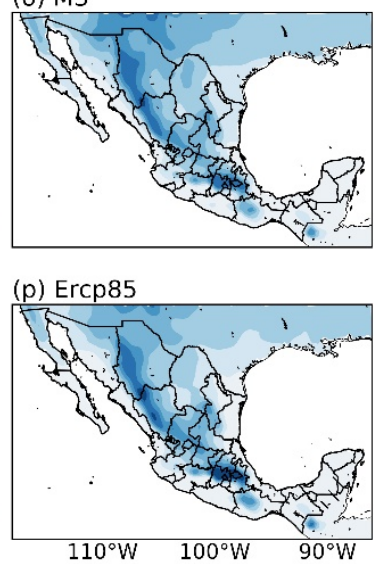

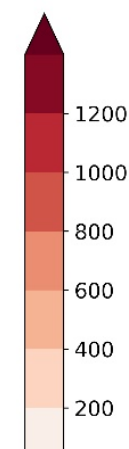

0

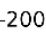

$-400$

$-600$

$-800$

$-1000$

$-1200$

Figure 6. Change in CDD ( ${ }^{\circ} \mathrm{C}$ days) during 2080-2099 for (a) M1, (b) M2, (c) M3, and (d) Ercp26 following the RCP2.6. (e-h) similar to (a-d) but for RCP8.5. Change in HDD ( ${ }^{\circ} \mathrm{C}$ days) during 2080-2099 for (i) M1, (j) M2, (k) M3, and (l) Ercp26 following the RCP2.6. (m-p) similar to (i-1) but for RCP8.5. Hatched lines mean non-significant change at the $95 \%$ confidence interval.

The simulations revealed an increase of $\operatorname{CDD}\left(200^{\circ} \mathrm{C}\right.$ days $<\Delta \mathrm{CDD}<400{ }^{\circ} \mathrm{C}$ days $)$ in the northwestern, south, and pacific coast regions of Mexico for Ercp26 (Figure 6d). Ercp26 shows fewer regions with an increase in CDD compared to the near future (Figure 4d) under the RCP2.6 scenario, consequently less energy requirements for cooling; the latter is consistent with an emission-reduction scenario, that is to say, in this scenario, a decrease in $\mathrm{CO}_{2}$ emissions at the middle of the 21st century is achieved by a considerable improvement of energy efficiency, replacement of unabated use of fossil fuels by renewable energy, nuclear power, etc. [28]. Meanwhile, under the RCP8.5, the Ercp85 (Figure 6h) shows an increase in $\mathrm{CDD}\left(\triangle \mathrm{CDD}>600{ }^{\circ} \mathrm{C}\right.$ days) over the whole country, which means more energy requirements for cooling. The change in CDD for Ercp85 (Figure 6h) is also greater compared to the near-future (Figure $4 \mathrm{~h}$ ), which is consistent with an emission-increase scenario; in this scenario the emissions grow thus by about a factor of three over the course of the 21st century, mainly as a result of both high demand and high fossil-intensity of the energy sector [29].

In turn, we only found a slight decrease of $\operatorname{HDD}\left(-400{ }^{\circ} \mathrm{C}\right.$ days $<\Delta \mathrm{HDD}<-200{ }^{\circ} \mathrm{C}$ days) in Central Mexico, and over mountain regions in Durango (DU) and Chihuahua (CH) for Ercp26 (Figure 61). Similar to CDD, Ercp26 shows fewer regions with a decrease in HDD compared to the near future (Figure 41) under the emission reduction scenario, RCP2.6. Also under this scenario, in the far-future, Mexico could have several regions with less warm conditions [36] than in the near-future. On the other hand, under the RCP8.5, the ensemble (Figure 6p) shows a substantial decrease in $\operatorname{HDD}\left(-1200{ }^{\circ} \mathrm{C}\right.$ days $<\Delta \mathrm{HDD}<-600^{\circ} \mathrm{C}$ days $)$ over the Northwestern, North, and Central Mexico; the latter implies hotter regions, and 
less energy requirements for heating $[37,38]$. The change in HDD for Ercp85 (Figure 6p) is greater compared to the near-future (Figure $4 \mathrm{p}$ ), which is consistent with the RCP8.5 extreme emission-increase scenario [29].

In Figure 7 , we show the change in $m\left(\Delta m=m_{\text {far-future }}-m_{\text {reference }}\right)$ of $\overline{C D D}$ (Figure 7a,b) and $\overline{H D D}$ (Figure 7c,d) for both RCP2.6 (boxplots in black) and RCP8.5 (boxplots in red). Figure 7a shows that the highest $\Delta m$ values for simulations M1 to M3 and Ercp will be under the RCP8.5. Figure $7 \mathrm{~b}$ shows that positive values of $\Delta m$ for each state are expected in both RCP scenarios, yet under the RCP8.5 $\Delta m$, could be higher in all states of Mexico, with exceptions in Mexico City (MC) and Tlaxcala (TL), which are non-typical values of $\Delta m$. Meanwhile, Figure $7 \mathrm{c}$ shows that the lowest $\Delta m$ values of $\overline{H D D}$ for simulations M1 to $\mathrm{M} 3$ and Ercp will be under the RCP8.5. Figure 7d shows that negative values of $\Delta m$ of $\overline{H D D}$ for each state are expected in both RCP scenarios but under the RCP8.5 $\Delta m$, could be lower in almost all states in Mexico.

(a)

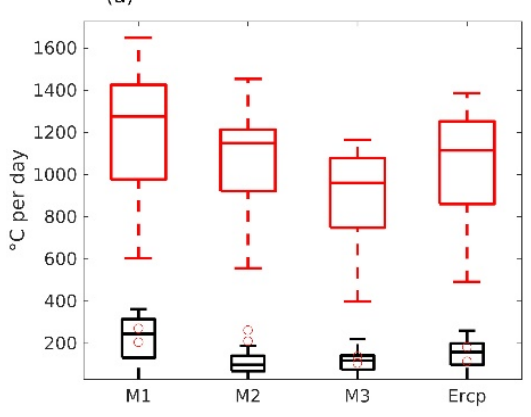

(c)

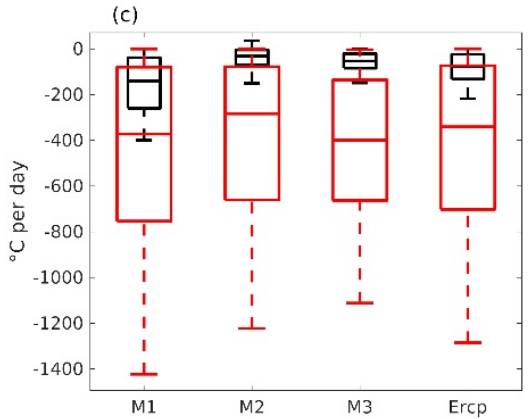

(b)

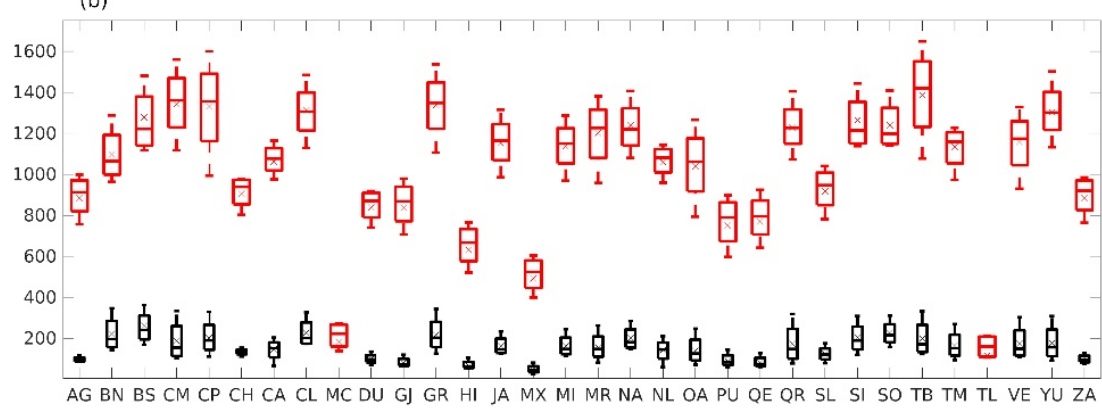

- RCP2.6

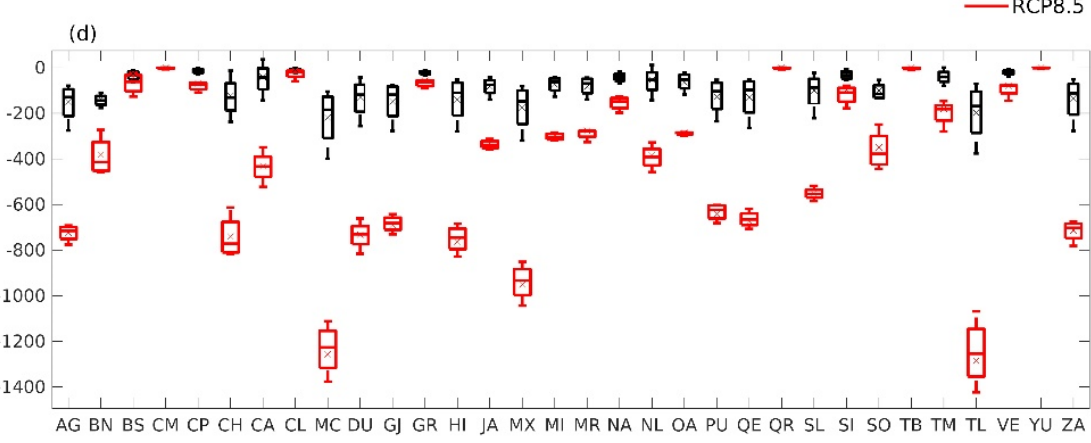

Figure 7. Change in $\overline{C D D}\left({ }^{\circ} \mathrm{C}\right.$ days) during 2080-2099 for (a) M1, M2, M3, and Ercp for the 32 states of Mexico. The open circle $(\bigcirc)$ denotes atypical values of $\Delta m$, and (b) in each of the 32 states of Mexico for M1, M2, M3 and Ercp. (c,d) same as $(\mathbf{a}, \mathbf{b})$, respectively, but for the change in $\overline{H D D}$. The cross $(\mathrm{x})$ in $(\mathbf{b}, \mathbf{d})$ indicates the $\Delta m$ for Ercp.

\section{Discussion}

Our results suggest that CDD will increase in the near- (Figures $4 a-h$ and $5 a, b$ ) and far- (Figures $6 \mathrm{a}-\mathrm{h}$ and $7 \mathrm{a}, \mathrm{b}$ ) future periods compared to the reference period. In contrast to CDD, we found that the HDD will decrease for both near- (Figures $4 i-p$ and $5 c, d$ ) and far- (Figures 6i-p and $7 c, d$ ) future periods with respect to the reference period, which is consistent with previous works $[6,10,11]$. The average change in $\overline{C D D}$ for the whole country for RCP 8.5 at the end of the century (Table 5) is smaller by an order of magnitude compared to that in Christenson et al. (2006) for Switzerland; and about one fourth compared to that in [6] for China. However, the average change in $\overline{H D D}$ (Table 5) is comparable to that found in [6] for China. 
Table 5. The average change over Mexico in $\overline{C D D}$, and $\overline{H D D}$ during near- (2041-2060) and far(2080-2099) future relative to the reference (1995-2014) period in the ensembles Ercp26 and Ercp85. Changes are expressed in degree-days and percent $\left({ }^{\circ} \mathrm{C}\right.$ days $\left.(\%)\right)$ for $\overline{C D D}$ and $\overline{H D D}$.

\begin{tabular}{ccccc}
\hline & \multicolumn{2}{c}{ RCP 2.6 } & \multicolumn{2}{c}{ RCP 8.5 } \\
\hline & Near-Ref & Far-Ref & Near-Ref & Far-Ref \\
\hline$\overline{C D D}$ & $187(16)$ & $145(12)$ & $408(34)$ & $1016(86)$ \\
$\overline{H D D}$ & $-106(-18)$ & $-81(-14)$ & $-216(-36)$ & $-410(-69)$ \\
\hline
\end{tabular}

We computed the difference between the 2080-2099 and 2041-2060 periods for both DD the CDD and the HDD (Figure 8). Under the lowest forcing level, simulations show less increase in $\mathrm{CDD}$ for the far-future (Figure 8a-d) compared to the near-future; this suggests that the immediate change in people's idiosyncrasy regarding natural-resource uses may have a direct impact on future energy requirements for getting thermal comfort. Similarly, for the HDD the models show less decrease for the far future (Figure 8e-h) compared to the near future. We believe this can be explained in terms of the warming decreases projected in the RCP2.6 scenario from a $0.4-1.1^{\circ} \mathrm{C}$, peak in 2050 , to $0.2-1.0^{\circ} \mathrm{C}$ by 2100 , reflecting the expected high radiative forcing at the middle of the century and its subsequent decline [35]. Nevertheless, to achieve a decrease in warming by 2100 , and consequently less increase in CDD compared to the near-future, several vital conditions need to be met immediately; for example, broad participation of countries and sectors in GHG emissions reduction [28].
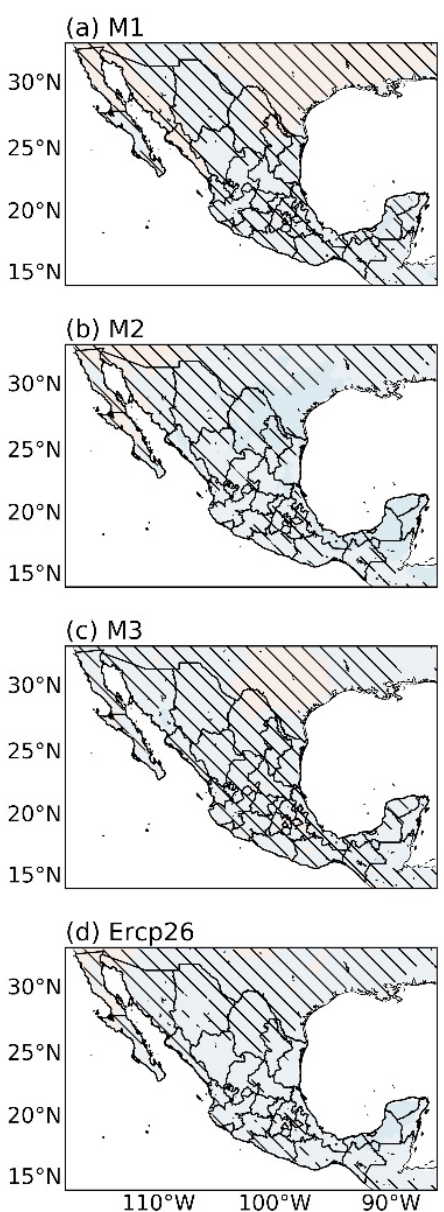
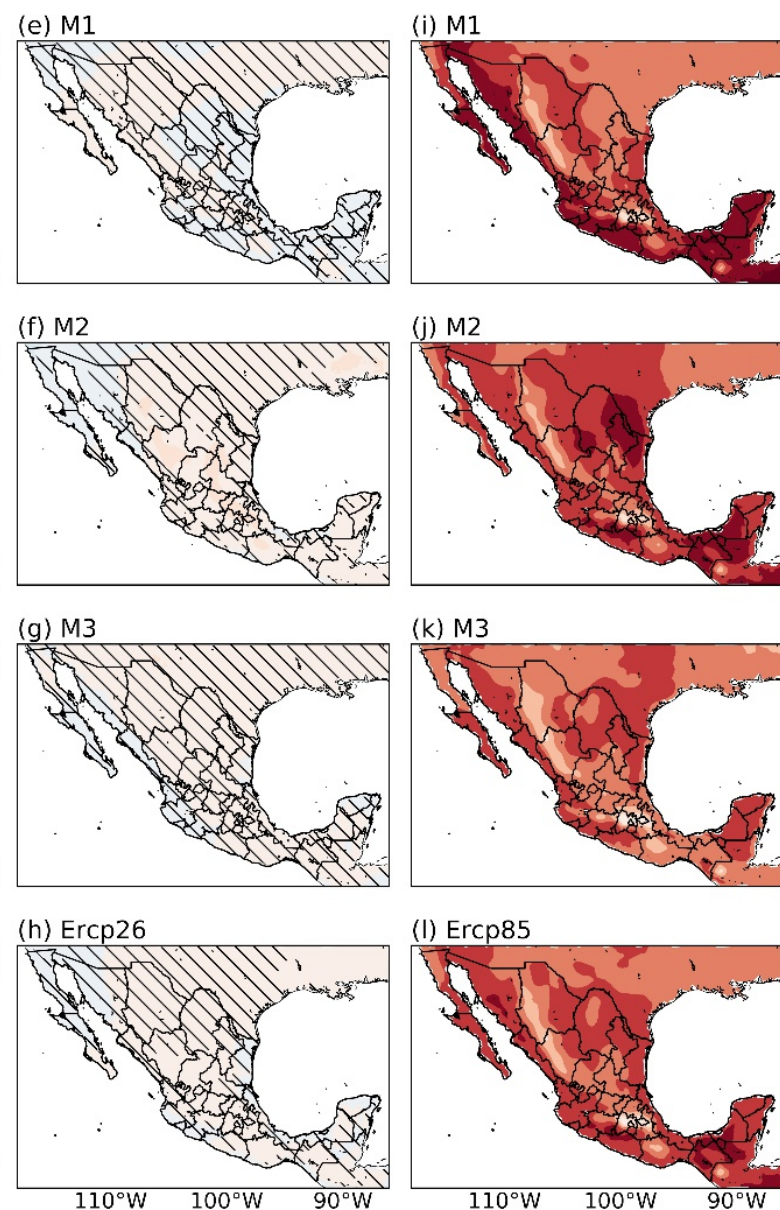
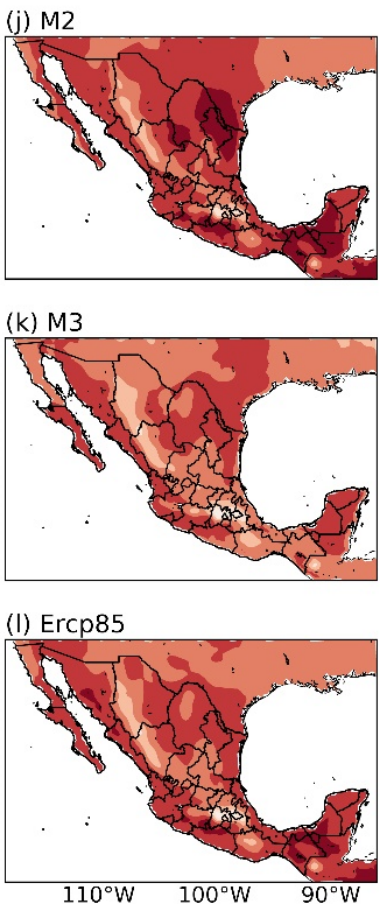
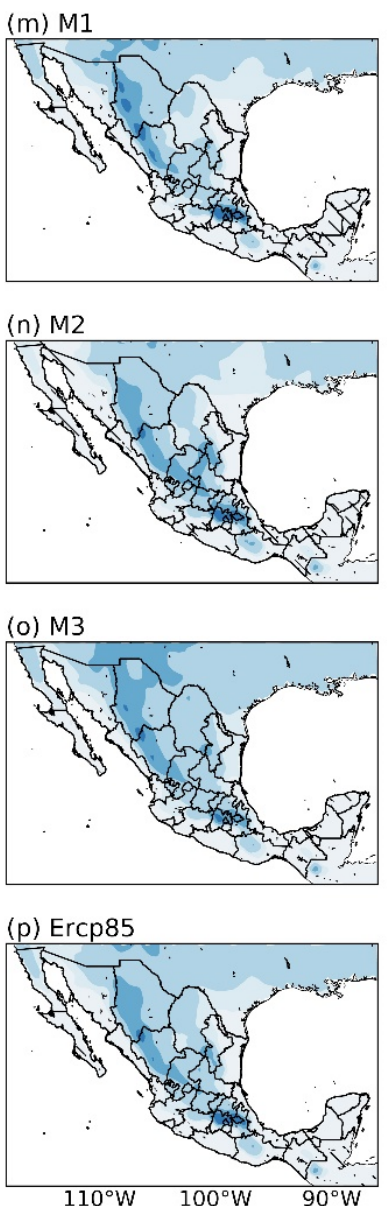

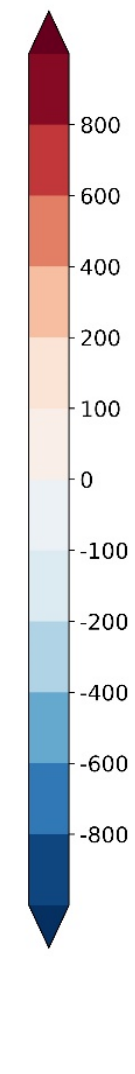

Figure 8. The difference of CDD ( ${ }^{\circ} \mathrm{C}$ days) between the 2080-2099 and 2041-2060 period for (a) M1, (b) M2, (c) M3, and (d) Ercp26 following the RCP2.6. (e-h) similar to (a-d) but for HDD. The difference of CDD ( ${ }^{\circ} \mathrm{C}$ days) between the 2080-2099 and 2041-2060 period for (i) M1, (j) M2, (k) M3, and (1) Ercp85 following the RCP8.5. (m-p) similar to (i-1) but for HDD. Hatched lines mean non-significant change at the $95 \%$ confidence interval. 
For the highest radiative forcing scenario in all simulations, we found larger values in CDD for the far-future (Figure 8i-1) compared to the near-future. In contrast to CDD, the simulations revealed smaller values in HDD for the far- future (Figure $8 \mathrm{~m}-\mathrm{p}$ ) compared with the near-future. The latter could be because the warming increase projected in the RCP8.5 scenario approaches $3.7^{\circ} \mathrm{C}$ by 2100 [35]; since the RCP8.5 scenario combines assumptions about high population and energy use that lead in the long-term to high energy demand and GHG emissions (in the absence of climate-change policies; [29]).

The different behavior in the change of DD between the end-of-century and midcentury (Figure 8 ) for the RCP2.6/RCP8.5 seems to be the response of the regional climate model, RegCM4, to the radiative forcing trend ([39], and references therein).

The implications of the increase in CDD in Northern Mexico are related to a higher energy requirement to satisfy artificial cooling needs through air conditioning systems. This fact is particularly important in most of the Mexican territory since, according to [40], the government subsidy is for fossil-fuel energy production, which negatively affects the well-being of Mexican families. This is a vital sign that under a scenario without emission control, societies will depend even more on electricity. Therefore, we believe that at this time it is compulsory to work hard to search for and validate energy resources that are renewable and friendly to the environment.

\section{Conclusions}

We used the RegCM4 model driven by different GCMs and RCP scenarios to analyze future changes in CDD and HDD over Mexico. This was done after assessing the model performance in reproducing the present-day conditions. The assessment revealed that the model evaluation run (simulations M1 to M3, and the reference ensemble) reproduced the values and spatial patterns of CDD and HDD realistically. However, all simulations and the reference ensemble (Eref) have a warm bias, mainly over northwestern Mexico and a cold bias in the high and coastal regions, consistent with previous RegCM4 results in the CAM domain $[21,23]$. We found that CDD (HDD) might be increased (decreased) in the future compared to the reference period for both RCP2.6 and RCP8.5. The results indicated that under the RCP2.6 scenario, simulations show less increase (decrease) in CDD (HDD) for the far-future compared to the near-future. This behavior might be explained as a response to the expected peak in radiative forcing at mid-century and its subsequent decline. However, to achieve the radiative forcing decline, several vital conditions would need to be met.

In contrast to the lowest forcing level scenario, for the RCP8.5 we found-for all simulations-a raising (down) in CDD (HDD) for the far future compared to the near future. This greater increase (decrease) could be explained by the response of RegCM4 to the warming increase projected for 2100; in the absence of climate change policies in an extreme scenario, high population and energy-intensity increases could lead in the long term to higher energy demand and GHG emissions. Our results are an important sign that, in the future, under a scenario without emission control, society could depend even more on electricity; therefore, at this time, we must work hard and fast in the search and validation of energy sources that are renewable and friendly to the environment. Work is required to investigate future energy consumption in Mexico in terms of DD for different temperature thresholds in a climate change context. That is, more research on DD over Mexico is needed, as it is required to generate information and models about energy consumption under different periods and climate change scenarios. We think the information generated in this work for the different states of Mexico is important since it could contribute to the implementation of public policies on energy depending on the particular situation of each state of Mexico. Collaborations between research institutions, authorities, and companies in charge of energy supply will be vital for this. In this way, models can be generated that project energy consumption and price behavior under such scenarios. We believe this will help in designing strategies on energy administration and supply. 
Supplementary Materials: The following are available online at https:/ /www.mdpi.com/article/10 .3390 / atmos12091131/s1. Figure S1: The 20-yr average of CDD ( ${ }^{\circ} \mathrm{C}$ days) for the reference period for (a) Livneh, (b) CPC, and (c) ERA5. Difference in CDD as percentage (\%) between RegCM4 and observations for (d) M0 minus Livneh, (e) M0 minus CPC, (f) M0 minus ERA5. (g)-(i) similar to (d)-(f) but for M1. (j)-(l) similar to (g)-(i) but for M2. (m)-(o) similar to (j)-(l) but for M3. (p)-(r) similar to (m)-(o) but for Eref. Period 1995-2014, with the exception of Livneh, which is for 1994-2013. Figure S2: The 20-yr average of HDD ( ${ }^{\circ} \mathrm{C}$ days) for the reference period for (a) Livneh, (b) CPC, and (c) ERA5. Difference in HDD as percentage (\%) between RegCM4 and observations for (d) M0 minus Livneh, (e) M0 minus CPC, (f) M0 minus ERA5. (g)-(i) similar to (d)-(f) but for M1. (j)-(l) similar to (g)-(i) but for M2. (m)-(o) similar to (j)-(l) but for M3. (p)-(r) similar to (m)-(o) but for Eref. Period 1995-2014, with the exception of Livneh, which is for 1994-2013.

Author Contributions: Conceptualization, A.C.-S. and O.R.-A.; Formal analysis, A.C.-S.; Investigation, J.A.T.-A.; Methodology, A.C.-S.; Software, A.C.-S.; Supervision, E.G.P.; Validation, O.R.-A.; Visualization, A.C.-S. and E.G.P.; Writing—original draft, A.C.-S.; Writing—review \& editing, O.R.-A., J.A.T.-A. and E.G.P. All authors have read and agreed to the published version of the manuscript.

Funding: This work was supported by the Instituto Nacional de Investigaciones Forestales Agricolas y Pecuarias (INIFAP) of Mexico; Centro de Investigación Científica y de Educación Superior de Ensenada (CICESE); The Abdus Salam International Centre for Theoretical Physics (ICTP).

Institutional Review Board Statement: Not applicable.

Informed Consent Statement: Not applicable.

Data Availability Statement: Regional climate simulations data are publicly available via the Earth System Grid Federation website (https: / / esgf-data.dkrz.de/search/cordex-dkrz/, date of access: 30 August 2021).

Acknowledgments: The first author gratefully acknowledges the Instituto Nacional de Investigaciones Forestales Agricolas y Pecuarias (INIFAP), experimental station Pabellon, for all support in carrying this research out. We gratefully acknowledge the Abdus Salam International Centre for Theoretical Physics (ICTP) for the RegCM4 simulations. EGP's research is supported by CONACYT (Mexico). We also gratefully acknowledge the three anonymous reviewers for helping us to improve this work.

Conflicts of Interest: The authors declare no conflict of interest.

\section{References}

1. IPCC. Climate Change 2013: The physical science basis. In Contribution of Working Group I to the 5th Assessment Report of the Intergovernmental Panel on Climate Change; Stocker, T.F., Qin, D.H., Plattner, G.K., Tignor, M., Eds.; Cambridge University Press: Cambridge, UK, 2013.

2. Giorgi, F. Climate change hot-spots. Geophys. Res. Lett. 2006, 33, L08707. [CrossRef]

3. Şen, Z.; Kadioğlu, M. Heating degree-days for arid regions. Energy 1998, 23, 1089-1094. [CrossRef]

4. Kadioglu, M.; Şen, Z. Degree-Day Formulations and Application in Turkey. J. Appl. Meteorol. 1999, 38, 837-846. [CrossRef]

5. Al-Hadhrami, L. Comprehensive review of cooling and heating degree days characteristics over Kingdom of Saudi Arabia. Renew. Sustain. Energy Rev. 2013, 27, 305-314. [CrossRef]

6. Shi, Y.; Gao, X.; Xu, Y.; Giorgi, F.; Chen, D. Effects of climate change on heating and cooling degree days and potential energy demand in the household sector of China. Clim. Res. 2016, 67, 135-149. [CrossRef]

7. Büyükalaca, O.; Bulut, H.; Yilmaz, T. Analysis of variable-base heating and cooling degree-days for Turkey. Appl. Energy 2001, 69, 269-283. [CrossRef]

8. Spinoni, J.; Vogt, J.; Barbosa, P. European degree-day climatologies and trends for the period 1951-2011. Int. J. Climatol. 2015, 35, 25-36. [CrossRef]

9. Mistry, M.N. Historical global gridded degree-days: A high-spatial resolution database of CDD and HDD. Geosci. Data J. 2019, 6, 214-221. [CrossRef]

10. Christenson, M.; Manz, H.; Gyalistras, D. Climate warming impact on degree- days and building energy demand in Switzerland. Energy Convers. Manag. 2006, 47, 671-686. [CrossRef]

11. Shi, Y.; Zhang, D.; Xu, Y.; Zhou, B. Changes of heating and cooling degree days over China in response to global warming of $1.5^{\circ} \mathrm{C}, 2{ }^{\circ} \mathrm{C}, 3{ }^{\circ} \mathrm{C}$ and $4{ }^{\circ} \mathrm{C}$. Adv. Clim. Chang. Res. 2018, 9, 192-200. [CrossRef]

12. Coppola, E.; Raffaele, F.; Giorgi, F.; Giuliani, G.; Xuejie, G.; Ciarlo, J.M.; Sines, T.R.; Torres-Alavez, J.A.; Das, S.; di Sante, F.; et al. Climate hazard indices projections based on CORDEX-CORE, CMIP5 and CMIP6 ensemble. Clim. Dyn. 2021, 57, 1293-1383. [CrossRef] 
13. Peña-Gallardo, R.; Medina-Ríos, A.; Segundo-Ramírez, J. Analysis of the solar and wind energetic complementarity in Mexico. J. Clean. Prod. 2020, 268, 122323. [CrossRef]

14. Cámara de Diputados México. Ley para el Aprovechamiento de Energías Renovables y el Financiamiento de la Transición Energética. D. Of. La Fed. 1-16. 2013. Available online: https://www.cre.gob.mx/documento/3870.pdf (accessed on 1 May 2020).

15. Pérez-Denicia, E.; Fernández-Luqueño, F.; Vilariño-Ayala, D.; Montaño-Zetina, L.M.; Maldonado-López, L.A. Renewable energy sources for electricity generation in Mexico: A review. Renew. Sustain. Energy Rev. 2017, 78, 597-613. [CrossRef]

16. Giorgi, F.; Jones, C.; Asrar, G.R. Addressing Climate Information Needs at the Regional Level: The CORDEX Framework. World Meteorol. Organ. Bull. 2009, 58, 175-183.

17. Giorgi, F.; Coppola, E.; Solmon, F.; Mariotti, L.; Sylla, M.B.; Bi, X.; Elguindi, N.; Diro, G.T.; Nair, V.; Giuliani, G.; et al. RegCM4: Model description and preliminary tests over multiple CORDEX domains. Clim. Res. 2012, 52, 7-29. [CrossRef]

18. Giorgi, F.; Gutowski, W.J. Regional dynamical downscaling and the cordex initiative. Annu. Rev. Environ. Resour. 2015, 40, 467-490. [CrossRef]

19. Torres-Alavez, J.A.; Das, S.; Corrales-Suastegui, A.; Coppola, E.; Giorgi, F.; Raffaele, F.; Bukovsky, M.S.; Ashfaq, M.; Salinas, J.A.; Sines, T. Future projections in the climatology of global low-level jets from CORDEX-CORE simulations. Clim. Dyn. 2021, 57, 1551-1569. [CrossRef]

20. Torres-Alavez, J.A.; Glazer, R.; Giorgi, F.; Coppola, E.; Gao, X.; Hodges, K.I.; Das, S.; Ashfaq, M.; Reale, M.; Sines, T. Future projections in tropical cyclone activity over multiple CORDEX domains from RegCM4 CORDEX-CORE simulations. Clim. Dyn. 2021, 57, 1507-1531. [CrossRef]

21. Fuentes-Franco, R.; Coppola, E.; Giorgi, F.; Pavia, E.G. Assessment of RegCM4 simulated inter-annual variability and daily-scale statistics of temperature and precipitation over Mexico. Clim. Dyn. 2014, 42, 629-647. [CrossRef]

22. Fuentes-Franco, R.; Coppola, E.; Giorgi, F.; Pavia, E.G.; Diro, G.T.; Graef, F. Inter-annual variability of precipitation over Southern Mexico and Central America and its relationship to sea surface temperature from a set of future projections from CMIP5 GCMs and RegCM4 CORDEX simulations. Clim. Dyn. 2015, 45, 425-440. [CrossRef]

23. Cavazos, T.; Luna-Niño, R.; Cerezo-Mota, R.; Fuentes-Franco, R.; Méndez, M.; Pineda Martinez, L.F.; Valenzuela, E. Climatic trends and regional climate models intercomparison over the CORDEX-CAM (Central America, Caribbean, and Mexico) domain. Int. J. Climatol. 2020, 40, 1396-1420. [CrossRef]

24. Dee, D.P.; Uppala, S.M.; Simmons, A.J.; Berrisford, P.; Poli, P.; Kobayashi, S.; Andrae, U.; Balmaseda, M.A.; Balsamo, G.; Bauer, P.; et al. The ERA-Interim reanalysis: Configuration and performance of the data assimilation system. Q. J. R. Meteorol. Soc. 2011, 137, 553-597. [CrossRef]

25. Taylor, K.E.; Stouffer, R.J.; Meehl, G.A. An overview of CMIP5 and the experiment design. Bull. Am. Meteorol. Soc. 2012, 93, 485-498. [CrossRef]

26. Moss, R.H.; Edmonds, J.A.; Hibbard, K.A.; Manning, M.R.; Rose, S.K.; Van Vuuren, D.P.; Carter, T.R.; Emori, S.; Kainuma, M.; Kram, T.; et al. The next generation of scenarios for climate change research and assessment. Nature 2010, 463, 747-756. [CrossRef] [PubMed]

27. van Vuuren, D.P.; Edmonds, J.; Kainuma, M.; Riahi, K.; Thomson, A.; Hibbard, K.; Hurtt, G.C.; Kram, T.; Krey, V.; Lamarque, J.-F.; et al. The representative concentration pathways: An overview. Clim. Chang. 2011, 109, 5. [CrossRef]

28. van Vuuren, D.P.; Stehfest, E.; den Elzen, M.G.J.; Kram, T.; van Vliet, J.; Deetman, S.; Isaac, M.; Goldewijk, K.K.; Hof, A.; Beltran, A.M.; et al. RCP2.6: Exploring the possibility to keep global mean temperature increase below $2{ }^{\circ} \mathrm{C} . \mathrm{Clim} . \mathrm{Chang}$. 2011, 109,95 . [CrossRef]

29. Riahi, K.; Rao, S.; Krey, V.; Cho, C.; Chirkov, V.; Fisher, G.; Kindermann, G.; Nakicenovic, N.; Rafaj, P. RCP8.5: A scenario of comparatively high greenhouse gas emissions. Clim. Chang. 2011, 109, 33-57. [CrossRef]

30. Sánchez-Rodríguez, R.; Cavazos, T. Capítulo 1: Amenazas naturales, sociedad y desastres. In Conviviendo con la Naturaleza: El Problema de los Desastres Asociados a Fenómenos Hidrometeorológicos y Climáticos en México; Cavazos, E.T., Ed.; Ediciones ILCSA: Tijuana, Mexico, 2015; pp. 1-45. ISBN 978-607-8360-39-0.

31. Livneh, B.; Bohn, T.J.; Pierce, D.W.; Munoz-Arriola, F.; Nijssen, B.; Vose, R.; Cayan, D.R.; Brekke, L. A spatially comprehensive, hydrometeorological data set for Mexico, the U.S., and Southern Canada 1950-2013. Sci Data 2015, 2, 150042. [CrossRef] [PubMed]

32. Hersbach, H.; Bell, B.; Berrisford, P.; Hirahara, S.; Horányi, A.; Muñoz-Sabater, J.; Nicolas, J.; Peubey, C.; Radu, R.; Schepers, D.; et al. The ERA5 global reanalysis. Q. J. R. Meteorol. Soc. 2020, 146, 1999-2049. [CrossRef]

33. Copernicus Climate Change Service (C3S) ERA5: Fifth Generation of ECMWF Atmospheric Reanalyses of the Global Climate. Copernicus Climate Change Service Climate Data Store (CDS). 2017. Available online: https://cds.climate.copernicus.eu/ cdsapp\#!/ home (accessed on 15 May 2020).

34. Rhoda, R.; Burton, T. Geo-Mexico: The Geography and Dynamics of Modern Mexico; Sombrero Books: Ladysmith, BC, Canada, 2010; $274 \mathrm{p}$.

35. Nazarenko, L.; Schmidt, G.; Miller, R.; Tausnev, N.; Kelley, M.; Ruedy, R.; Russell, G.; Aleinov, I.; Bauer, M.; Bauer, S.; et al. Future climate change under RCP emission scenarios with GISS ModelE2. J. Adv. Model. Earth Syst. 2015, 7, 244-267. [CrossRef]

36. van Vuuren, D.P.; Riahi, K. The relationship between short-term emissions and long-term concentration targets. Clim. Chang. 2011, 104, 793-801. [CrossRef] 
37. Colorado-Ruiz, G.; Cavazos, T.; Salinas, J.A.; De Grau, P.; Ayala, R. Climate change projections from Coupled Model Intercomparison Project phase 5 multi-model weighted ensembles for Mexico, the North American monsoon, and the mid-summer drought region. Int. J. Climatol. 2018, 38, 5699-5716. [CrossRef]

38. United States Environmental Protection Agency (EPA). 2020. Available online: https://www.epa.gov/climate-indicators/climatechange-indicators-heating-and-cooling-degree-days (accessed on 6 June 2020).

39. Ramaswamy, V.; Collins, W.; Haywood, J.; Lean, J.; Mahowald, N.; Myhre, G.; Naik, V.; Shine, K.P.; Soden, B.; Stenchikov, G.; et al. Radiative Forcing of Climate: The Historical Evolution of the Radiative Forcing Concept, the Forcing Agents and their Quantification, and Applications. Meteorol. Monogr. 2018, 59, 14.1-14.101. [CrossRef]

40. Londoño-Pineda, A.A.; Baena-Rojas, J.J. Análisis de la relación entre los subsidios al sector energético y algunas variables vinculantes en el desarrollo sostenible en México en el periodo 2004-2010. Gestión y Política Pública 2017, 26, 491-526. Available online: http:/ / www.scielo.org.mx/scielo.php?script=sci_arttext\&pid=S1405-10792017000200491\&lng=es\&tlng=es (accessed on 9 June 2020). 